\title{
VOLTAGE STABILITY ANALYSIS USING STATCOM
}

\author{
by \\ Umang Patel \\ BEng in Electrical Engineering, Gujarat University, Dec 2011
}

\author{
A MRP \\ presented to Ryerson University \\ in partial fulfillment of the \\ requirements for the degree of \\ Master of Engineering \\ in the program of
}

Electrical and Computer Engineering

Toronto, Ontario, Canada, 2017

(C) Umang Patel 2017 


\section{AUTHOR'S DECLARATION}

I hereby declare that I am the sole author of this project. This is a true copy of the project, including any required final revisions, as accepted by my examiners.

I authorize Ryerson University to lend this project to other institutions or individuals for the purpose of scholarly research.

I further authorize Ryerson University to reproduce this project by photocopying or by other means, in total or in part, at the request of other institutions or individuals for the purpose of scholarly research.

I understand that my project may be made electronically available to the public. 


\section{ABSTRACT}

\section{VOLTAGE STABILITY ANALYSIS USING STATCOM}

Umang Patel

Master of Engineering,

Electrical and Computer Engineering

Ryerson University, 2017

Power system stability is gaining importance because of unusual growth in power system.

Day by day use of nonlinear load and other power electronics devices created distortions in the system which creates problems of voltage instability. Voltage stability of system is major concerns in power system stability. When a transmission network is operated near to their voltage stability limit it is difficult to control active-reactive power of the system. Our objectives are the analysis of voltage stability margin and active-reactive power control in proposed system which includes model of STATCOM with aim to analyse its behavior to improve voltage stability margin and active-reactive power control of the system under unbalanced condition. The study has been carried out using MATLAB Simulation program on three phase system connected to unbalanced three phase load via long transmission network and results of voltage and active-reactive power are presented. In future work, we can do power flow calculation of large power system network and find the weakest bus of the system and by placing STATCOM at that bus we can improve over all stability of the system 
Table of Contents

Author's declaration.................................................... ii

Abstract............................................................ iii

List of Figures........................................................

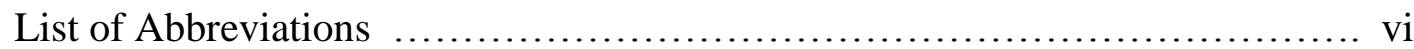

1 Introduction 1

$2 \quad$ Literature survey 2

$3 \quad$ Voltage stability assessment 4

3.1 Description of physical phenomenon 5

3.1.1 Time scale 5

3.1.2 Reactive power, system changes and voltage collapse 6

$\begin{array}{lll}3.2 & \text { Static voltage stability } & 7\end{array}$

3.3 Voltage stability analysis $\quad 8$

3.3.1 P-V and Q-V curves 8

3.3.2 P margin calculation by P-V curves 8

3.3.3 Q margin calculation by Q-V curves 8

$4 \quad$ STATCOM for voltage stability assessment 10

$5 \quad$ Modelling and simulation 15

$6 \quad$ Conclusion 24

References $\quad 25$ 
List of Figures

$\begin{array}{lll}3.1 & \text { Voltage collapse time scale } & 7\end{array}$

3.2 Real Power-Voltage (P-V) curve 9

$\begin{array}{lll}3.3 & \text { Reactive power-voltage }(\mathrm{Q}-\mathrm{V}) \text { curve } & 10\end{array}$

$\begin{array}{lll}4.1 & \text { Structure of STATCOM }\end{array}$

$\begin{array}{lll}4.2 & \text { STATCOM's schematic representation } & 12\end{array}$

4.3 Equivalent one-phase circuit of the STATCOM 13

$\begin{array}{ll}4.4 & \text { Lagging and leading currents }\end{array}$

4.5 Three-phase STATCOM's equivalent circuit 14

5.1 3-Phase system for voltage unbalancing in the system 15

$\begin{array}{lll}5.2 & \text { Voltage unbalancing at load side } & 15\end{array}$

5.3 Unbalancing and Distortion in source voltage and current 16

$\begin{array}{ll}5.4 & \text { Flickering and unbalancing condition }\end{array}$

$\begin{array}{lll}5.5 & \text { Sag and swell condition and voltage unbalancing } & 17\end{array}$

5.6 Active and Reactive Power due to unbalanced load 17

5.7 Uncompensated Reactive Power without STATCOM 18

5.8 Voltage Stability Assessment and Balancing using STATCOM 18 Circuit

5.9 Controlling circuit of STATCOM 19

$\begin{array}{lll}5.10 & \text { Voltage and current enhancement } 20\end{array}$

$\begin{array}{lll}5.11 & \text { load side voltage and current improvement } 20\end{array}$

$\begin{array}{lll}5.12 & \text { Three phase output current in p.u } & 21\end{array}$

5.13 Three phase output voltage and current at load side pure 21 sinusoidal after the STATCOM connection

5.14 Active and Reactive Power after STATCOM 22

5.15 Compensated Reactive with STATCOM 22

5.16 THD before STATCOM connection 23

$\begin{array}{lll}5.17 & \text { THD after STATCOM connection }\end{array}$ 


\section{List of Abbreviations}

- FACT: Flexible alternating current transmission systems

- STATCOM: Static Compensator

- THD: Total harmonic distortion

- VSC: Voltage source converter 


\section{Introduction}

Day by day electrical load demand is growing rapidly and to complete the electrical load demand generating stations like thermal, nuclear, and solar etc. are operating at their maximum capacity. At the other side, as per the demand growing several blackouts type major problems and power quality issues and voltage stability problems have occurred in the power system. In the year 2003 there were 6 major blackouts occurred in the countries like US, UK, Denmark, Sweden, and Italy. Those blackout problems are occurred due to increase in electrical power demand which creates complexity problems in interconnected power systems due to which the system operate closer to their stability limit.

There are two major characteristics in voltage stability study:

i. Voltage stability assessment which helps to identify the voltage stability margin in system

ii. Voltage instability mechanism analysis to identify the area and buses most susceptible to voltage collapse in power system.

Voltage stability problem is mainly associated with increase of load, voltage values beyond their normal values that will create voltage instability in the system at generating side and receiving side also. The main problem of voltage instability is that the voltage level at different locations slightly changes after the disturbance of any kind of fault, switching operation or transient. So, we can say that the voltage level variation or fluctuation is not a good indicator. The system operator needs performance monitoring and controlling of the system to determine how close the system is to the collapse and what the control actions should be carried out in that event of voltage stability problem or unbalancing condition. In recent years and trends there are lots of algorithms have been proposed for calculating voltage stability margin by power flow calculations and there are continuation methods were implemented for the voltage collapse point and it will also affect on load ability in the proposed system. Use of FACTS devices is found to be highly effective in preventing voltage instability. Owing to high cost the number of FACTS devices to be used should be minimized. Here in our project the study has been carried out using MATLAB Simulation program on three phase system connected to unbalanced three phase load via long transmission network and results of voltage and active-reactive power are presented. In future work, we can do power flow calculation of large power system network and find the weakest bus of the system and by placing STATCOM at that 
bus we can improve over all stability of the system. Response time of the STATCOM is $<10 \mathrm{~ms}$.

\section{Literature Review}

Puneet Chawla, Balwinder Singh_2013 [1] has represents P-V and Q-V curve methods for voltage stability improvement for real time data. The power flow program is developed in MATLAB using Newton Raphson method in this paper by the authors to achieve the proposed objectives. STATCOM is placed on the bus of transmission which is required to improve the voltage stability, which also improve the power transmission capability of the given transmission line. This work improves the understanding of power systems network and power flow calculations for the proposed system by the authors. With the use of shunt FACTS device such as STATCOM into the system the voltage unbalancing has been mitigated.

H. B. Nagesh and P. S. Puttaswamy _April 2013 [2] has been represented a methodology for selection of location for SVC based on static voltage stability analysis of the given power system. The STATCOM and SVC are used in the continuation power flow process for voltage stability analysis in this paper by the authors to enhance stability margin. The comparative study of SVC and STATCOM for voltage stability enhancement of the given system is described by the authors in this paper. The simulation results of this paper show that SVC and STATCOM both devices are capable of increasing voltage stability of the system and also improves the power transfer capability. Shwetal Patel and Bhavin Trivedi _Aug 2013 [3] has represents that the voltage stability problems in the power system are an important issue that must be taken into consideration in planning and operation of modern power system networks. The main information of power flow analysis is to find the magnitude and phase angle of the voltage at each bus and it also includes the active and reactive power flowing in each of the transmission lines.

This paper discusses the analysis of voltage stability of large power system using modal analysis technique. This method calculates specified number of the smallest Eigen values and associated eigenvectors of a reduced Jacobian matrix. The Eigen values each of which is associated with a reactive power variation provide a relative measure of the proximity to the voltage instability. The eigenvectors are used for describing the mode shape and to provide information about the network elements and generators participating in each mode. The least Eigen value indicates the proximity of the system to voltage 
instability. This method was used to determine the system components that contribute to the instability by using the factors involved. Thus, method is used to determine the optimal placement of inserting STATCOM at weak bus. A typical IEEE 30 bus system is used for this analysis and the result is presented for with and without STATCOM in this paper by the authors.

Kaushik. B. Patel and Sanjay. R. Vyas_Jan 2015 [4] has shown the reconstructed power systems with improved system transmission line and derive high operational efficiency and system security. The authors show that voltage stability is a reactive power problem and can be solved by providing adequate reactive power support at some critical buses. FACTS devices are being increasing used to provide not only the reactive power support but also to control other aspects of a power system. This paper will be based on the voltage stability analysis of IEEE 14 BUS and IEEE 30 BUS systems using STATCOM and UPFC devices. The author concluded that using same rating of STATCOM and UPFC, UPFC is more efficient and provide better voltage profile for given loading condition.

Sarita S. Bhole, Prateek Nigam_Feb 2015 [5] has been described that the increase in power demand has forced the power system to operate closer to its stability limit. Voltage Stability has become a major concern in power systems planning and operation. This problem has become very complex due to the continuous growing on system interconnections and demand for electricity and also due to economical and environmental constraints to properly expand the system.

The nature of voltage stability can be analysed by the production transmission and consumption of reactive power. One of the major causes of voltage instability is the reactive power unbalancing which occurs in stressed condition of power system. The FACTS devices play an important role in improving the performance of a power system, but these devices are very costly and hence need to be placed optimally in power system.

Balwant k. Mehta, Asso. Prof. P. J. Patel_2013 [6] has presents that one of the major causes of voltage instability is the increasing load demand. In this paper the effects of STATCOM on static voltage stability will be studied by the authors. The system reactive power handling capacity can be improved by using FACTS devices more effectively compared with the conventional methods and calculations. In this paper voltage stability assessment of the modified IEEE 6-bus test system with STATCOM is studied in this paper by the authors. 
Abhishek Gandhar, Balwinder Singh, and Rintu Khanna_2012 [7] has been described the simulation study of STATCOM a very popular FACTS Controller connected with the Distributed energy system. A combination of one wind turbine generator system and a Diesel generator system are used to design this distributed generation system. In this paper system Simulation investigate the capability of STATCOM for providing the dynamic compensation to the system and enhance the voltage stability of the interconnected system. In this paper the effective STATCOM is improving the Voltage profiles of all three loads .here active and reactive power profiles of wind power system and diesel power system are also analysed.

Tanaya Datta, PalukuruNagendra, SunitaHalder nee Dey, Subrata Paul_2013 [8] has presents a method to predict the voltage collapse point of power system incorporating two major FACTS devices i.e., Static VAR Compensator (SVC) and Static Synchronous Compensator (STATCOM) using a two-bus integrated equivalent system. Among SVC and STATCOM the second one provides better control over voltage stability and secures the voltage stable states in better way in all stages of system operation.

Le Ngoc Giang and Liu Kaipei_2014 [9] have been studied about the power system stability assessment with help of FACTS devices like STATCOM and SVC in the proposed system. The control strategy and simulation has been done for voltage stability enhancement with the help of STATCOM and SVC. The authors also show the performance comparison of SVC and STATCOM for stability enhancement and also for the power transfer capabilities of both the devices.

Neena Ramesh, B.V Sanker Ram and Vedam Subramanian_2012 [10] has represents the Q-V curve control topology for voltage stability of improvement of the given system using SVC and STATCOM devices. The Q-V curve methodology is one of the very popular methods but due to some drawbacks and complications the latest control techniques are not used this method. The simulation results show the stability margin using Q-V curve for the given power system.

\section{Voltage Stability Assessment}

There are lots of challenges that we face for online operation, monitoring and control of power system. First thing is the power system under the deregulated environment, in many parts of the world, are operated by several independent transmission operators. Among all these operators only limited number of information is exchanged primarily 
due to business competitions. This makes a study of the entire system harder than offline system. There are different classical methods for stability analysis requires complete information of the entire power system. They are also time consuming for a large power system. Second thing is the system stability is also subject to setting of various control devices which may be located outside the authorized area of control.

The increasing demand of electrical power makes the system to operate close to their stability conditions i.e. high line current, low voltage level and relatively high power angle differences which indicate the system is operating under heavy loading conditions. Due to that kind of problems system losing stability, islanding or voltage collapse can be occurred in the system. The main problem, that most of the utilities are facing, is to maintain voltage level within acceptable range. Analysis of voltage stability for operation and planning of a power system involves the examination of two main aspects i) How close the system is to voltage instability? and ii) The key contributing factors such as the weak buses, area involved in collapse and generators and transmission lines participating in the collapse when voltage instability occurs. First thing provides information regarding voltage security while the second thing provides information for modification of system and operation plan that can be implemented to improve the stability margin. These are the different methods which are normally utilized for voltage stability assessment and control. The use Flexible AC Transmission System (FACTS) controllers to provide voltage and power flow controls are increasing, so we can also use FACTS devices for voltage stability problems. In this chapter, we have represented the concept of voltage collapse and described some related topics of voltage collapse in the power system.

\subsection{DESCRIPTION OF PHYSICAL PHENOMENON}

This section represents some of the basic features of voltage collapse in power system. Here we have described very small and important features \& characteristics of voltage collapse in power system otherwise there are lots of research are already done and published in earlier times

\subsubsection{Time scales}

Voltage collapses take place on the following time periods ranging from seconds to hours:

i. Electromechanical transients and power electronics device operation which occurs only for few seconds in the system. 
ii. Operation of on load and off load taps changers and excitation limiter which is occurs for tens of seconds.

iii. Load recovery processes which occurs for time duration of several minutes.

The voltage collapse time scale 1 is known as transient time scale while time scales 2 and 3 is called as long term time scale for voltage stability analysis. Electromagnetic transients on transmission and distribution lines and synchronous machines are occurred for very fast and short time interval so due to that in our power system the Electromagnetic transients are removed as fast as possible due to that we can easily do the analysis of voltage and current in our power system. For a balanced three-phase system, the value of active power is equal to the sum of the power momentarily transferred by the three phases in the given system. At other side the value of reactive power at each phase is of a zero-mean amplitude power oscillation at twice to the system frequency.

Figure 3.1 shows the different range of voltage collapse in the power system. Voltage collapses can be classified as occurring in transient time scales alone or in the long-term time scale. Voltage collapses in the long-term time scale can include effects from the transient time scale; for example, a slow voltage collapse taking several minutes may end in a fast voltage collapse in the transient time scale.

\subsubsection{Reactive Power, System Changes, and Voltage Collapse}

Voltage collapse typically occurs on power systems which are over loaded, faulted and has reactive power unbalancing. Voltage collapse is system instability in which it involves many power system components and their variables at one time of interval and sometimes also involves an entire power system. Reactive power demands of load increases with increase in load and due to changes in load composition such as an increased proportion of compressor load. The main reasons for voltage collapse in the power system are over loading in the system, Generators \& synchronous condensers exceeding reactive power limit, Action of load tap changing transformer, Load recovery dynamics, Line tripping, Generator outages 


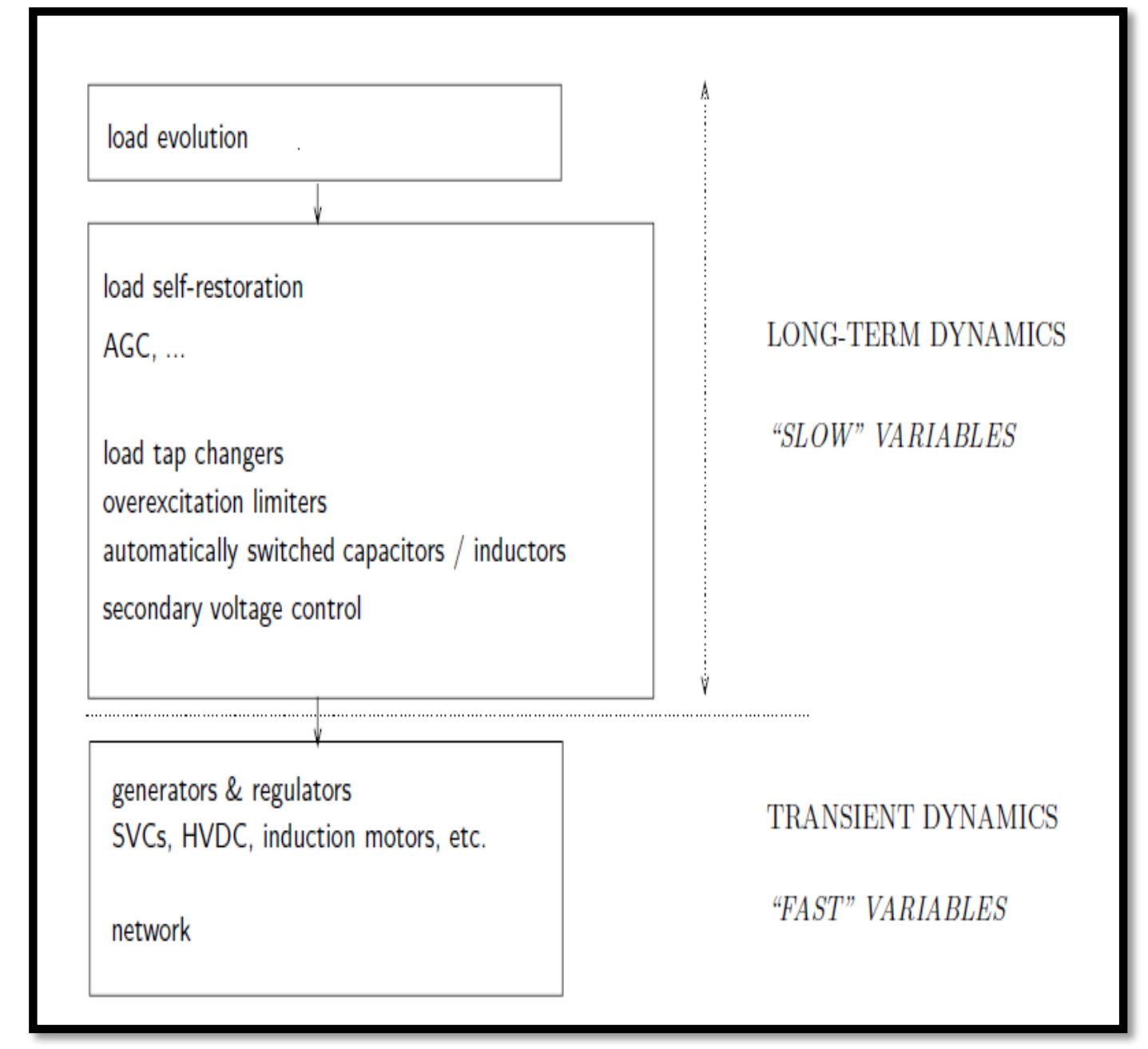

Figure 3.1 Voltage collapse time scale

\subsection{STATIC VOLTAGE STABILITY}

Main reason behind voltage instability is reactive power unbalancing. The load capability of a bus in the power system depends on the reactive power support of the bus received from the system. Therefore, the reactive power support must be local and adequate to satisfy the requirement of the proposed power system. There are two types of voltage stability based on the time frame simulation they are static voltage stability and dynamic voltage stability. Static voltage stability analysis involves the solution only based on algebraic equation and hence it is computationally less extensive than that of time required by dynamic stability analysis.

Static voltage stability is ideal for major studies in the power system for many precontingency and post-contingency cases in the power system. In the study and analysis of static voltage stability small changes in the power system used for reduction of reactive power and voltage declining. This phenomenon can be seen from the plot of the power 
transferred versus the voltage at receiving end characteristics. The plots are popularly referred to as P-V curves or Nose curves. Any further increase in active power transfer will always lead to rapid decrease in voltage magnitude. Before reaching the critical point in the given system the large voltage drop takes place due to more reactive power losses. Now only way to save the system from voltage collapse is by reducing the reactive power load or add additional reactive power prior to reaching the point of voltage collapse.

\subsection{VOLTAGE STABILITY ANALYSIS}

Different methods have been listed carrying out a steady state voltage stability analysis. The conventional methods can be broadly classified into the following types. [1].

i. P-V curve method for P loading margin

ii. Q-V Curve method for Q loading margin

iii. Sensitivity based Indices

iv. V-Q curve method for RRB

v. Modal Analysis.

\subsubsection{P-V AND Q-V CURVES}

The active power-voltage curves (P-V curve) is the most widely used method for voltage stability assessment. MW distance from the operating point to the critical voltage can be determined by P-V curve. Maximum power transfer capacity determines critical limits on the load bus, above which the power system maintains operation in steady-state mode. Using power flow simulation Q-V curves can be plotted. Curve represents the voltage at that bus vs reactive power at the same bus.

\subsubsection{P-MARGIN CALCULATION BY P-V CURVES}

The active power verses -Voltage curve of a single and constant power load connected via transmission line to an infinite-bus is shown in Fig.3.2., where P, real power of the load, is slowly varying parameter, and $\mathrm{V}$ is the voltage of the load bus. The regions given Fig.3.2 are associated to the parameter P. The power-flow equations fail to have a solution if active power is increased more. Maximum power transfer capacity determines critical limits on the load bus, above which the power system maintains operation in steady-state mode. The maximum power that can be transferred is calculated using P-V curve. The value transmissible power corresponds to a value of the voltage at bus till $\mathrm{V}=$ 
Vcrit after that further increase in power consequences in worsening of bus voltage. In the top portion of the curve system operates under stable condition and the bottom half system becomes unstable. Hence using P-V curves we can determine voltage collapse margin.

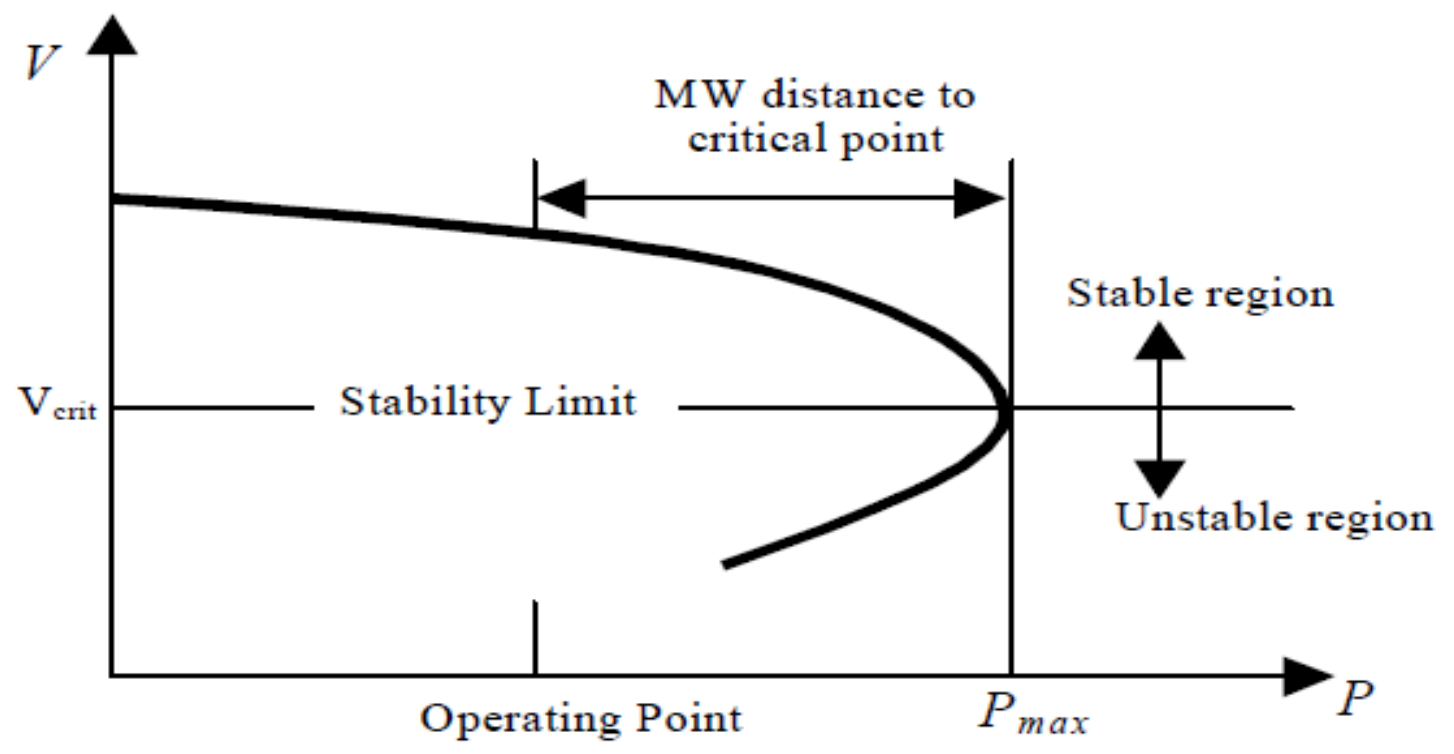

Fig 3.2- Real Power Voltage (P-V) curve

\subsubsection{Q-MARGIN CALCULATION BY Q-V CURVES}

The reactive power- voltage curve ( $\mathrm{Q}-\mathrm{V}$ curves) determines the MVAR distance from the operating point to the critical voltage. Fig.-3.3 a typical Q-V curve. It illustrates the sensitivity and variation of bus voltages with respect to reactive power absorptions or injections. In Fig.3.3, the Q axis represents the value of reactive power that can be added or removed from the bus in order to maintain a voltage at a given load. The reactive power margin can also be defined as the MVAR distance from the operating point to maximum reactive power. Also, as per the curve there is two possible value of the voltage at same value of power. 


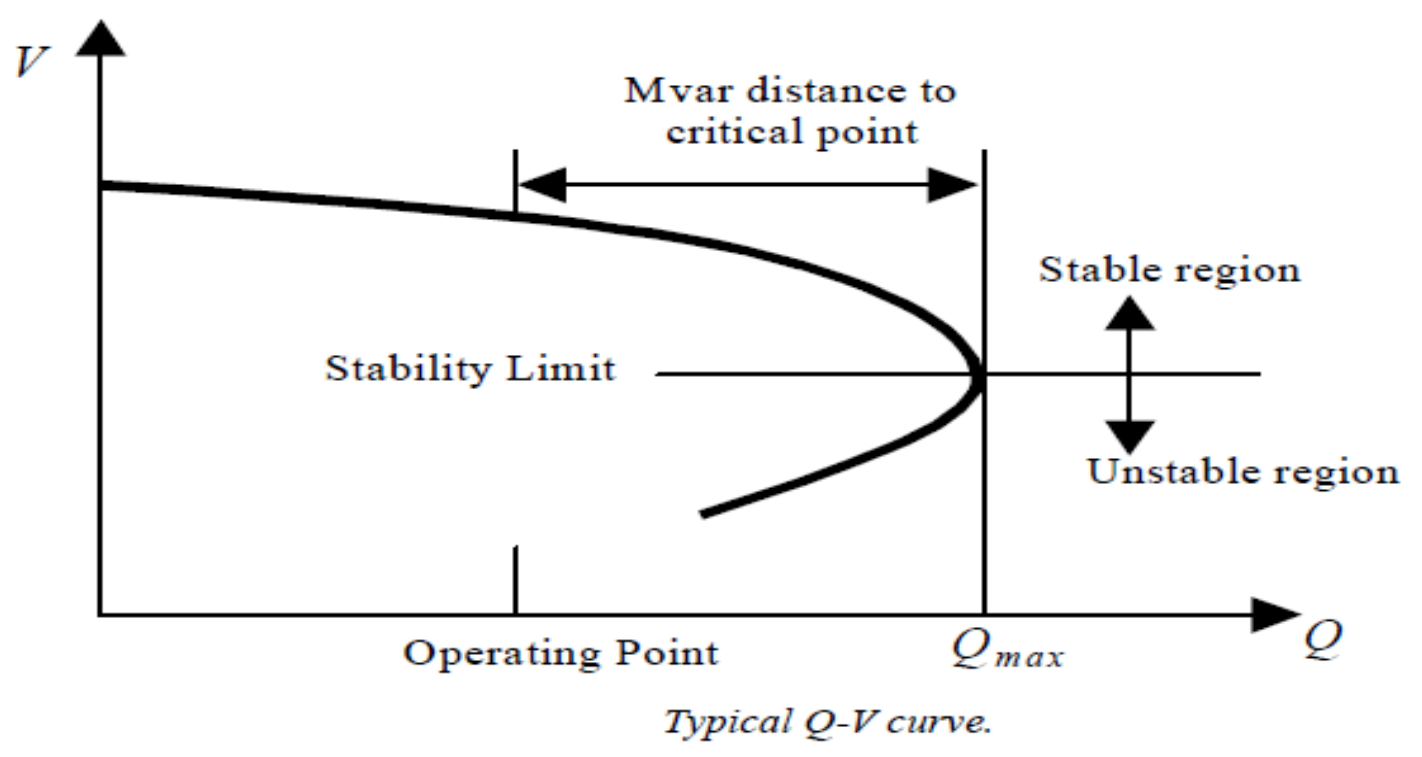

Fig-3.3 Reactive power-voltage (Q -V) curve

Power system would require very high current in order to produce the power when operated at lower voltage. That is why that portion of the curve is an unstable region. This project proposes the voltage stability assessment control method using STATCOM device with the PI and PWM based VSC converter controlling strategy and the sensitivity based method which determines the sensitivity of the reactive power injection of a generator to an injection of reactive power at a load bus to identify the coherent bus groups without drawing the P-V and Q-V curve in the system. The load buses are grouped in such a way that if two adjacent buses have similar generator branch sensitivity values within a reasonable range of 5 percent say it indicates that the system generators will be affected in a similar manner as load is increased at buses.

\section{STATCOM for Voltage Stability Assessment}

Major problem is power system is voltage stability. The different researchers and engineers have already done different research and study about the voltage stability improvement using different conventional topologies and they also represent the simulation results using different software for validating the results for voltage stability calculations. Now a day the different FACTS devices are normally becoming very popular for power quality problems. So, it is necessary to study about the FACTS devices for voltage stability enhancement also. Due to that the different compensating devices are used for that purpose like SVC and STATCOM. From those devices, here we 
consider the static synchronous compensator (STATCOM). The different literatures are also utilised in our project for the voltage stability assessment study. The other methods like Q-V curve can also be used for voltage stability of the proposed system. For voltage stability calculation, there are different methods which also shown in literature are singular value decomposition (SVD) and modal analysis (Eigen value), which identifies the most sensitive elements and the weakest point in the system which affects voltage stability. In modern power system analysis, operation, and control information such as load ability and voltage instability mechanisms are becoming very significant to operators in control centres. that means, the operators have to clear their concept not only for stability problems but also clear the concept due to which that problems are occurred. Due to all these, there is always a risk of voltage collapse which will cause some time the shutdown of entire power system and blackout problem also which will cause an inconvenience to the consumers and big loss to the Electrical utility companies. It is always a better practice to know about the weakest elements in the system and weakest buses and their maximum loading limit.

Voltage stability problem is mainly associated with increase of load, voltage values beyond their normal values that will create voltage instability in the system at generating side and receiving side also. The main problem of voltage instability is that the voltage level at different locations slightly changes after the disturbance of any kind of fault, switching operation or transient etc. So, we can say that the voltage level variation or fluctuation is not a good indicator. The system operator needs performance monitoring and controlling either online or offline modes to determine how close the system is to the collapse and what the control actions should be carried out in that event of voltage stability problem or unbalancing condition.

Figure 4.1 shows the structure of a static synchronous compensator (STATCOM) as a regulating device which is used in power system for power quality enhancement. It is based on voltage source converter (VSC) topology. If connected to a source of power, it can also provide active AC power. The mathematical model of the differential equation and the reactive power to be injected at the STATCOM node is given as: -

$$
\begin{gathered}
\mathrm{i}_{\mathrm{SH}}=\left(\mathrm{K}_{\mathrm{r}}\left(\mathrm{V}_{\mathrm{ref}}+\mathrm{v}_{\mathrm{POD}}-\mathrm{V}\right)-\mathrm{i}_{\mathrm{SH}}\right) / \mathrm{T}_{\mathrm{r}} \\
\mathrm{Q}=-\mathrm{i}_{\mathrm{SH}} \mathrm{V}
\end{gathered}
$$




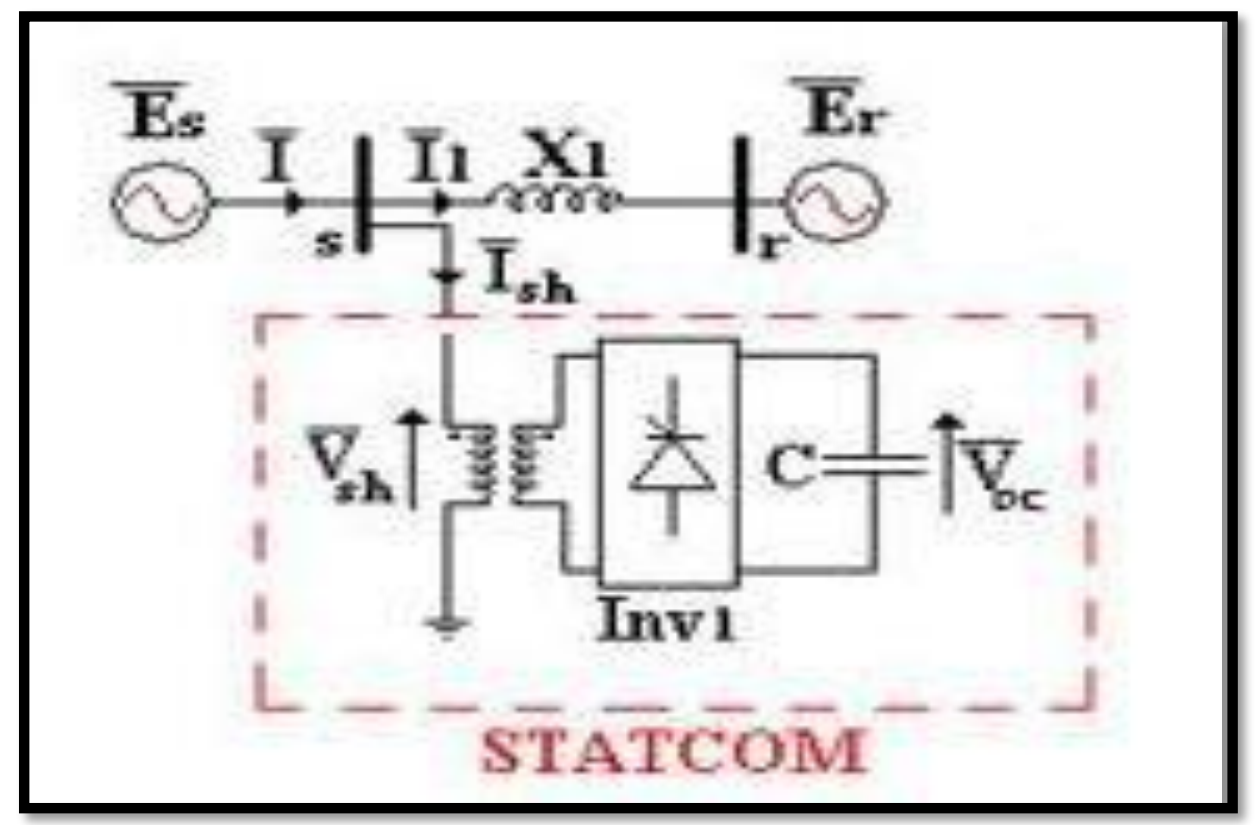

Fig4.1: Structure of STATCOM

STATCOM MODELLING A schematic representation of the single phase STATCOM is shown in Figure 4.2. It comprises of voltage source converter (VSC). The transformer is used as a link between the VSC and the system

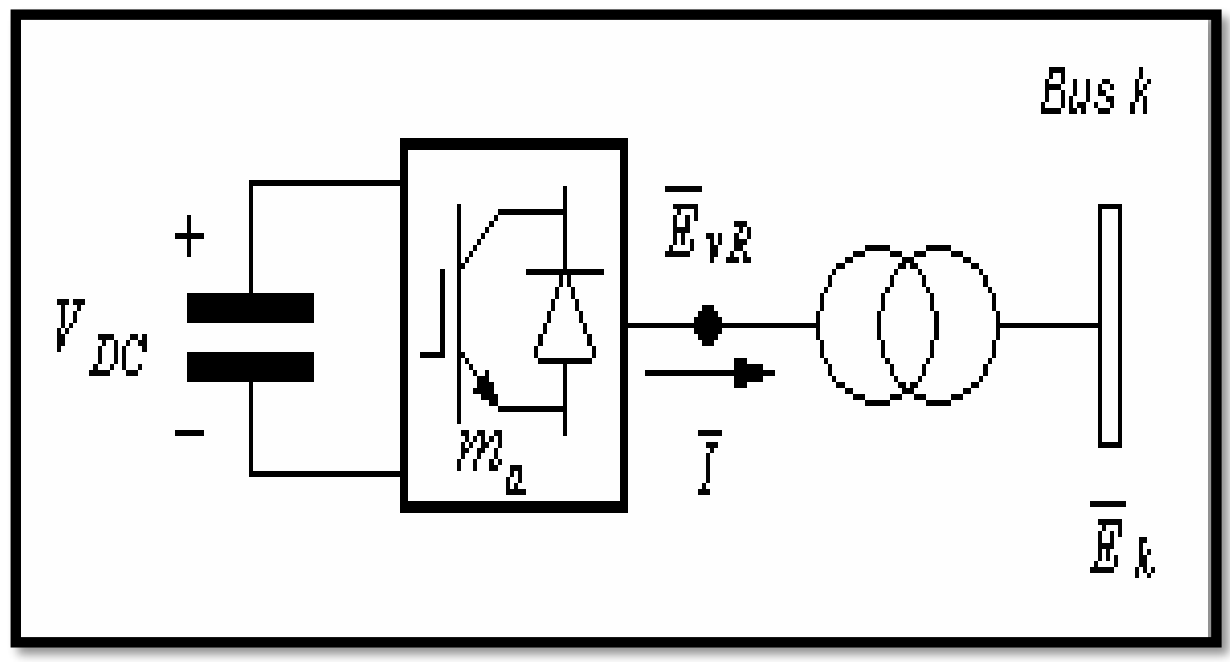

Fig.4.2. STATCOM's schematic representation

To understand basic operation of STATCOM, we can assume that transformer connected is lossless and its equivalent single phase circuit is shown if Figure 4.3, where $\mathrm{E}_{\mathrm{vR}}$ is that STATCOM terminal voltage and $E_{K}$ the voltage in power system bus. The basics of the STATCOM's operation is that the amplitude and phase angle of the voltage drop $\boldsymbol{A E x}$, Figure-4.3, can be controlled, defining the amount and direction of active and reactive power flows through the reactance. If we take $\theta k=0$ as the reference to simplify the 
formulation, the following equations $4.2,4.3$ and 4.4 are the voltage and power equations applied to the circuit

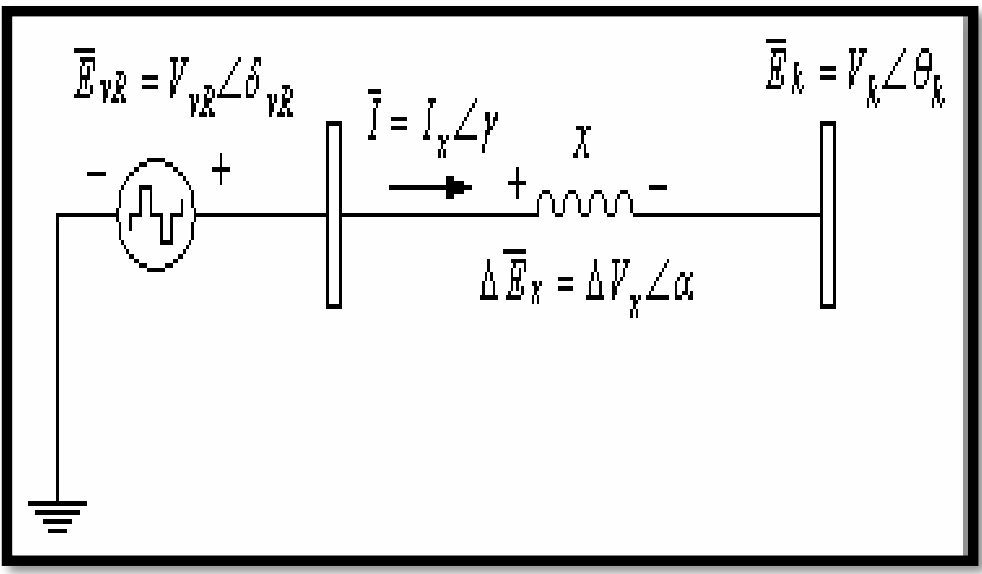

Fig-4.3. Equivalent one-phase circuit of the STATCOM

$$
P=\frac{V_{v R} V_{k}}{x} \sin \delta_{v R}
$$

$$
P=\frac{V_{v R} V_{k}}{x} \sin \delta_{v R}
$$

$$
Q=\frac{V_{v R}^{2}}{x}-\frac{V_{v R} V_{k}}{x} \cos \delta_{v R}
$$

A small amount of active power flows through voltage source converters to compensate for the power losses that exist in its interior, under the normal working condition. According to Fig. $4.3, \delta_{\mathrm{vR}}$ is slight different than $\theta k$. In Fig. $4.4 \mathrm{a}$ and $4.4 \mathrm{~b}$ represents space vector form of STATCOM.

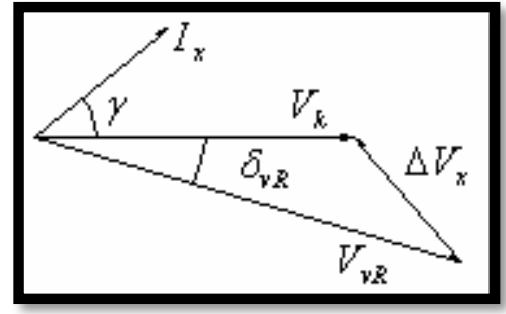

(a)

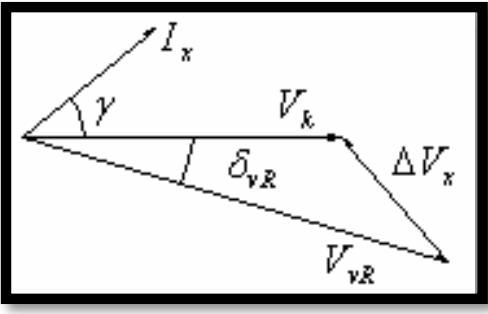

(b)

Figure 4.4 lagging and leading currents 
Fig. 4.4 (a) shows operating condition where $V v R>V k$, with a lagging power factor, in such circumstances, the STATCOM is absorbing active power from the system and giving reactive power to the same one. On the other hand, Figure4.4 (b) represents a operation condition where $(V v R<V k)$, a leading power factor; in this condition STATCOM absorbs active and reactive power from the system. With reference to Equation 4.1 to 4.3 and Fig. 4.4, if $\mathrm{Vk}$ is assumed to be constant, then by changing value of $\mathrm{VvR}$, SATATCOM can absorb or deliver reactive power to the system.

\section{Steady-state equation and equivalent circuit of STATCOM}

It is easy to get the three-phase model of STATCOM from single phase formulation. Shunt Voltage of STATCOM can be given by:

$$
E_{v R}^{\rho}=V_{v R}^{\rho}\left(\cos \delta_{v R}^{\rho}+j \operatorname{sen} \delta_{v R}^{\rho}\right)
$$

$\rho=$ phase quantities $a, b$, and $c$

Fig. 4.5 shows the equivalent circuit of the three-phase STATCOM in wye configuration. Using this model, we can derive steady-state equations in the form of three-phase power flow formulation. There are two unknow variables in this formulation, V $\rho v R y \delta \rho v R$

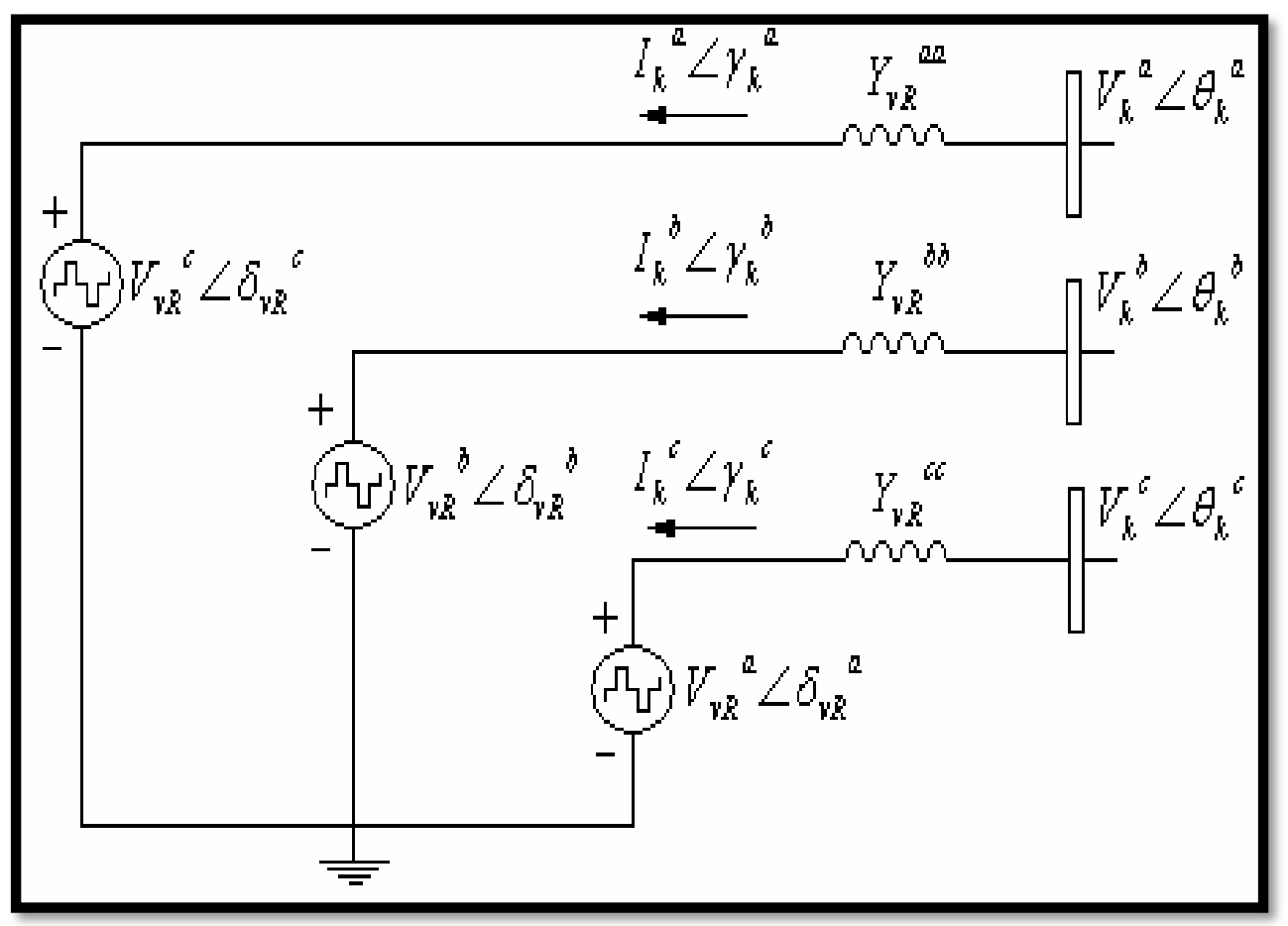

Fig.4.5 Three-phase STATCOM's equivalent circuit 


\section{Modelling and simulation}

The fig 5.1 shows the three-phase system without any facts device or controlling. There are one two distribution line are provided with R-L load. Due to the R-L load in the proposed system the output voltage and current values become unbalancing and their distortion and sag swell problems occurred are shown in the simulation results below: -

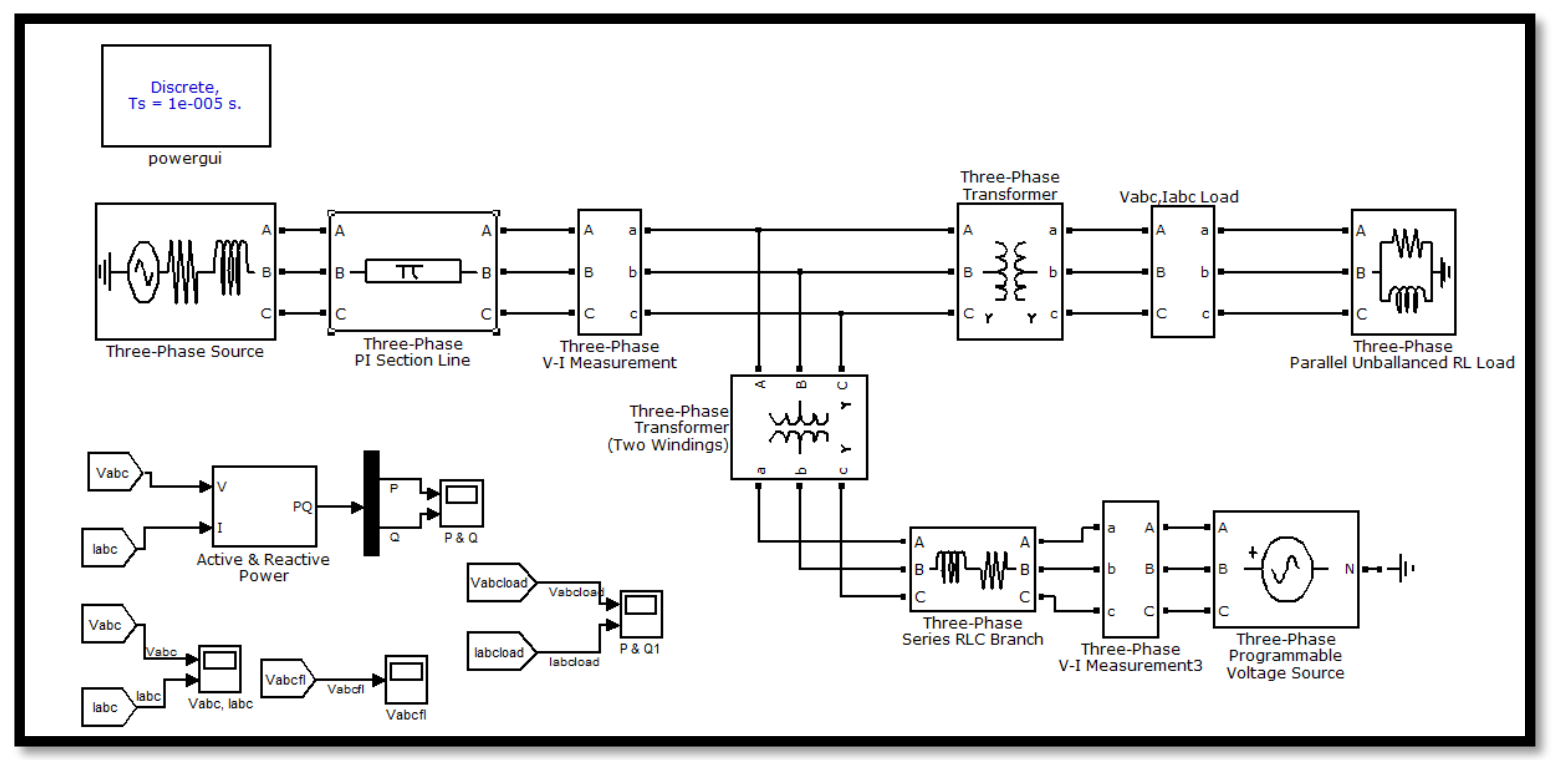

Fig 5.1-3-Phase system for voltage unbalancing in the system

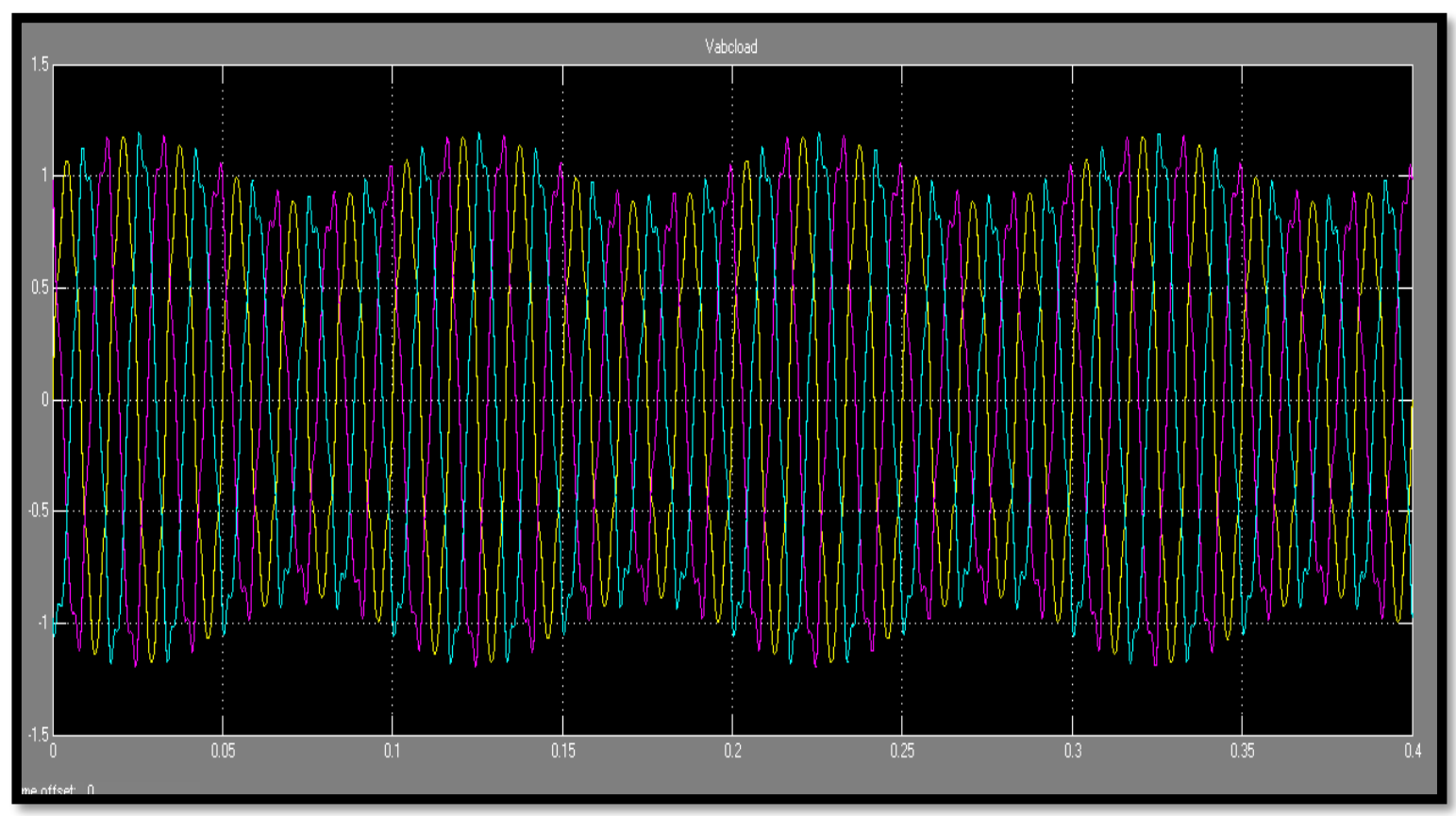

Fig 5.2- Voltage unbalancing at load side 


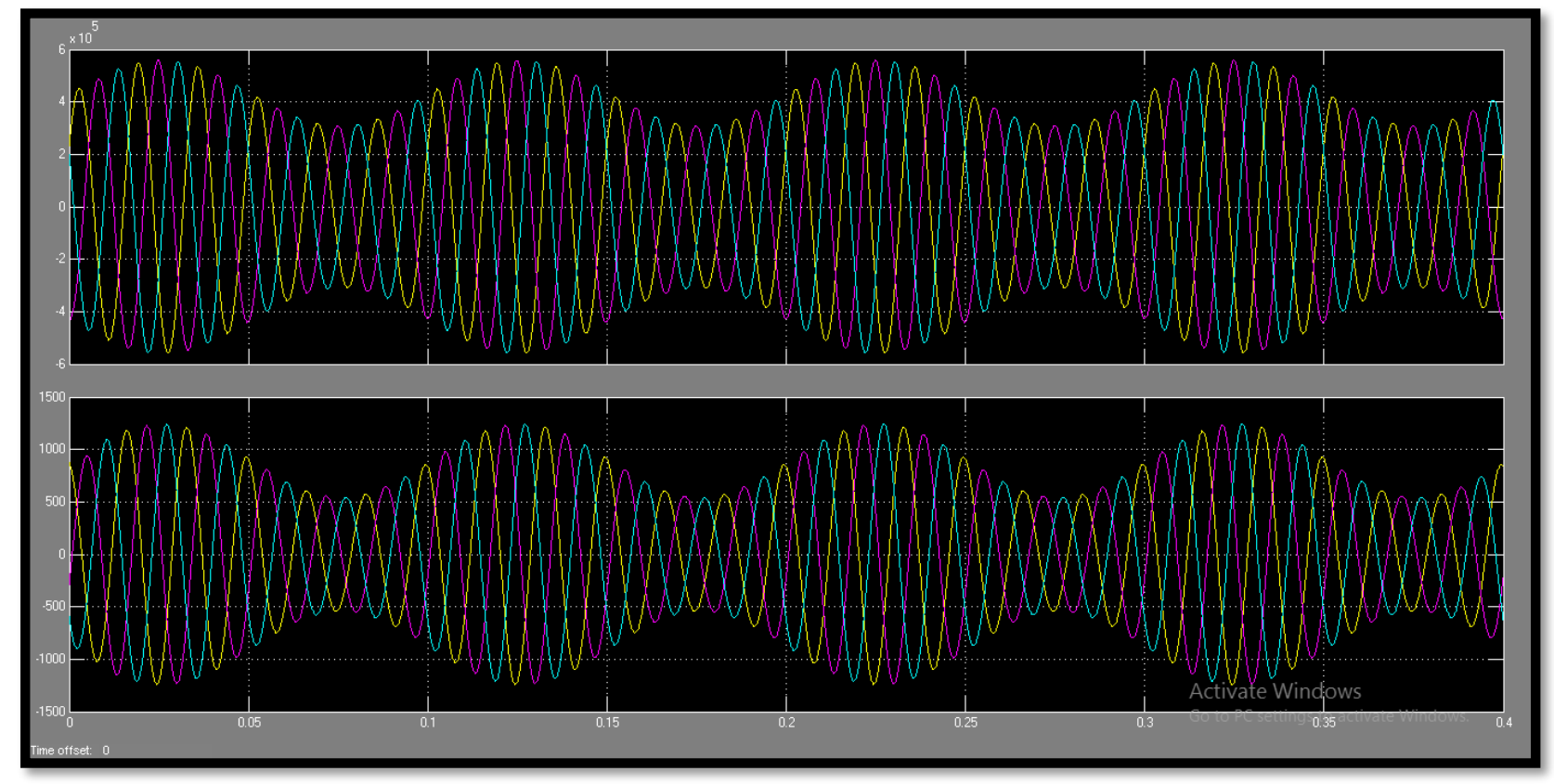

Fig 5.3 Unbalancing and Distortion in source voltage and current

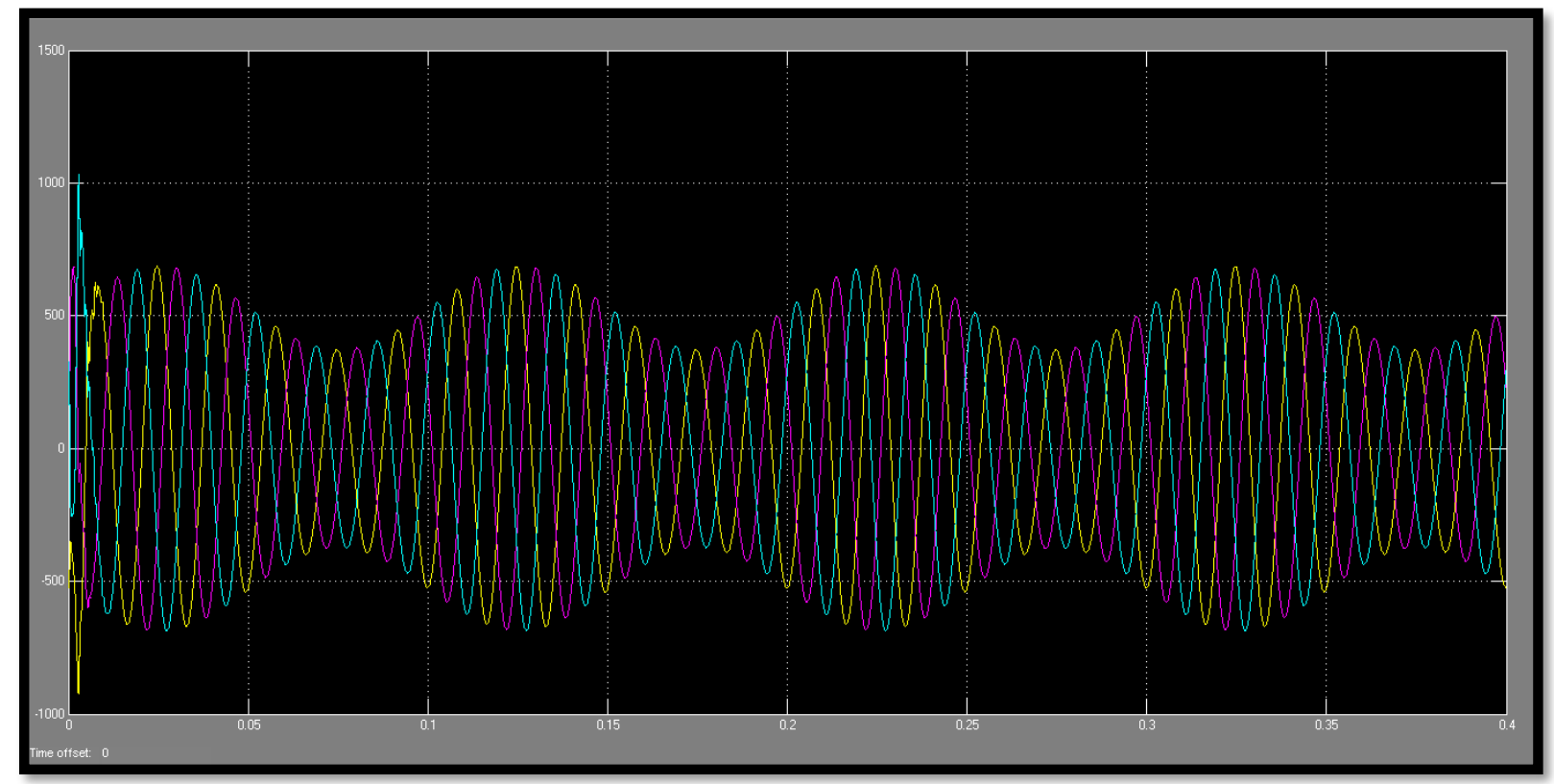

Fig 5.4 flickering and unbalancing condition 


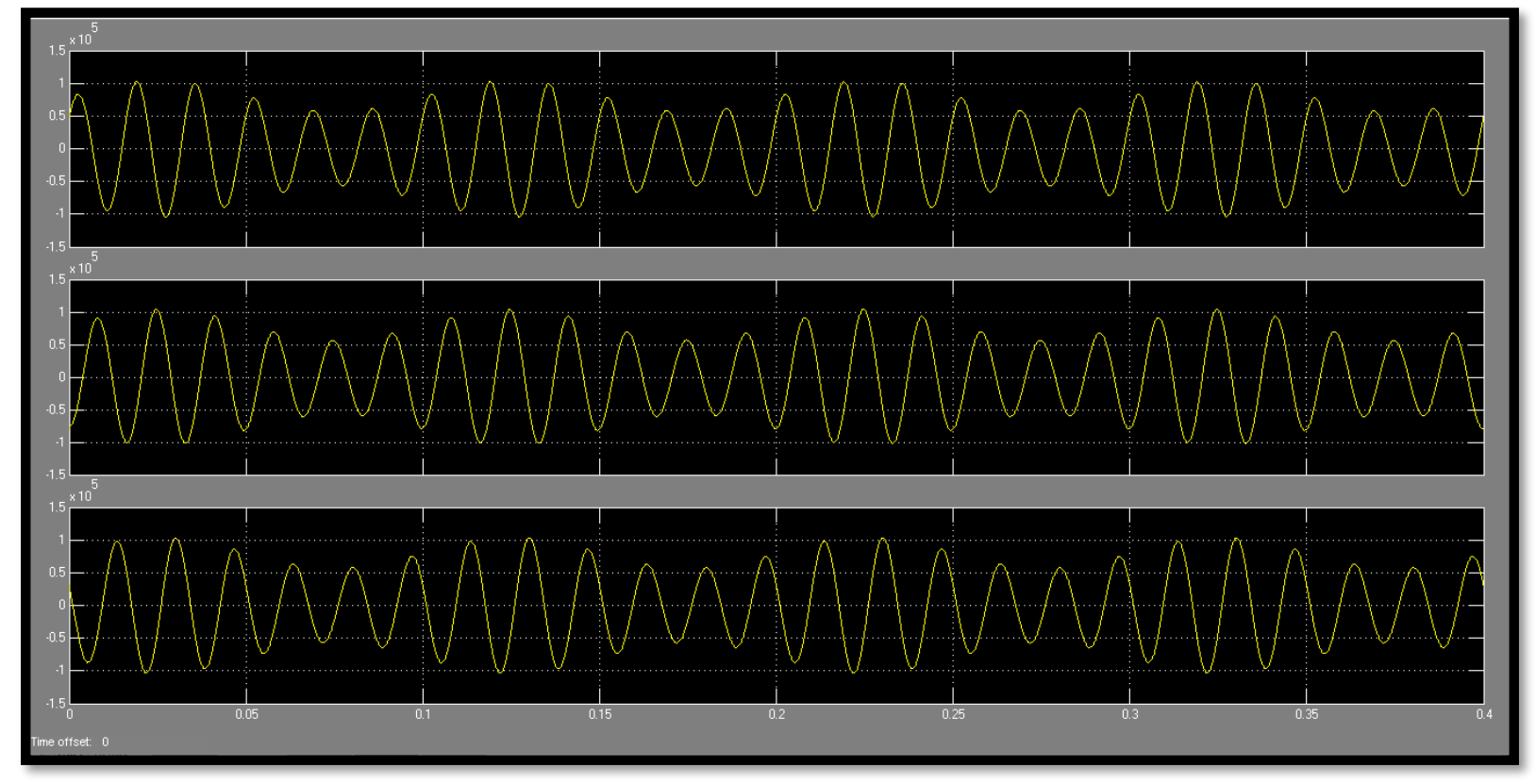

Fig 5.5-sag and swell condition and voltage unbalancing

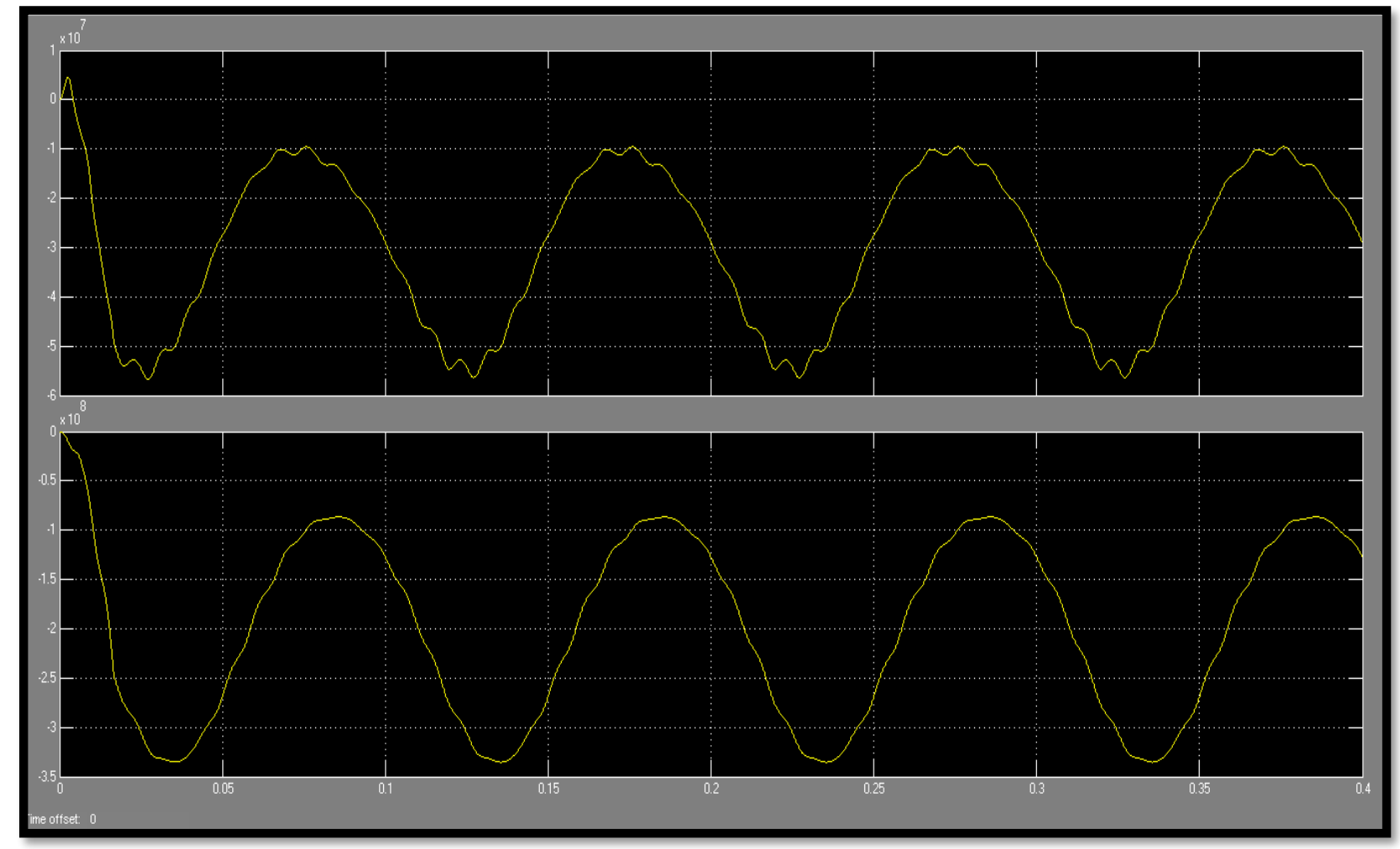

Fig 5.6- Active and Reactive Power due to unbalanced load 


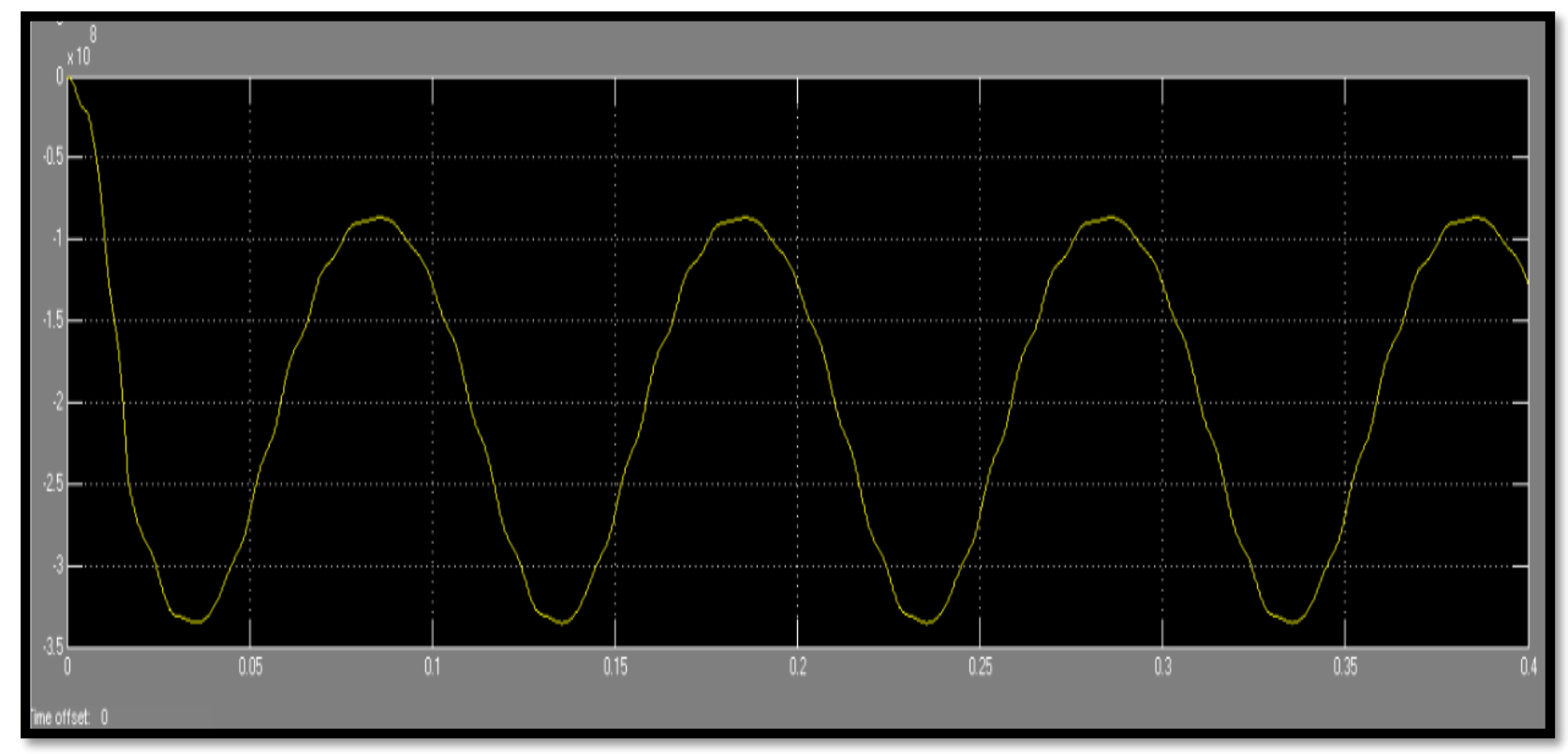

Fig 5.7-Uncompensated Reactive Power without STATCOM

\subsection{MATLAB Simulation for Voltage Stability and balancing in the 3-phase System}

\section{using STATCOM}

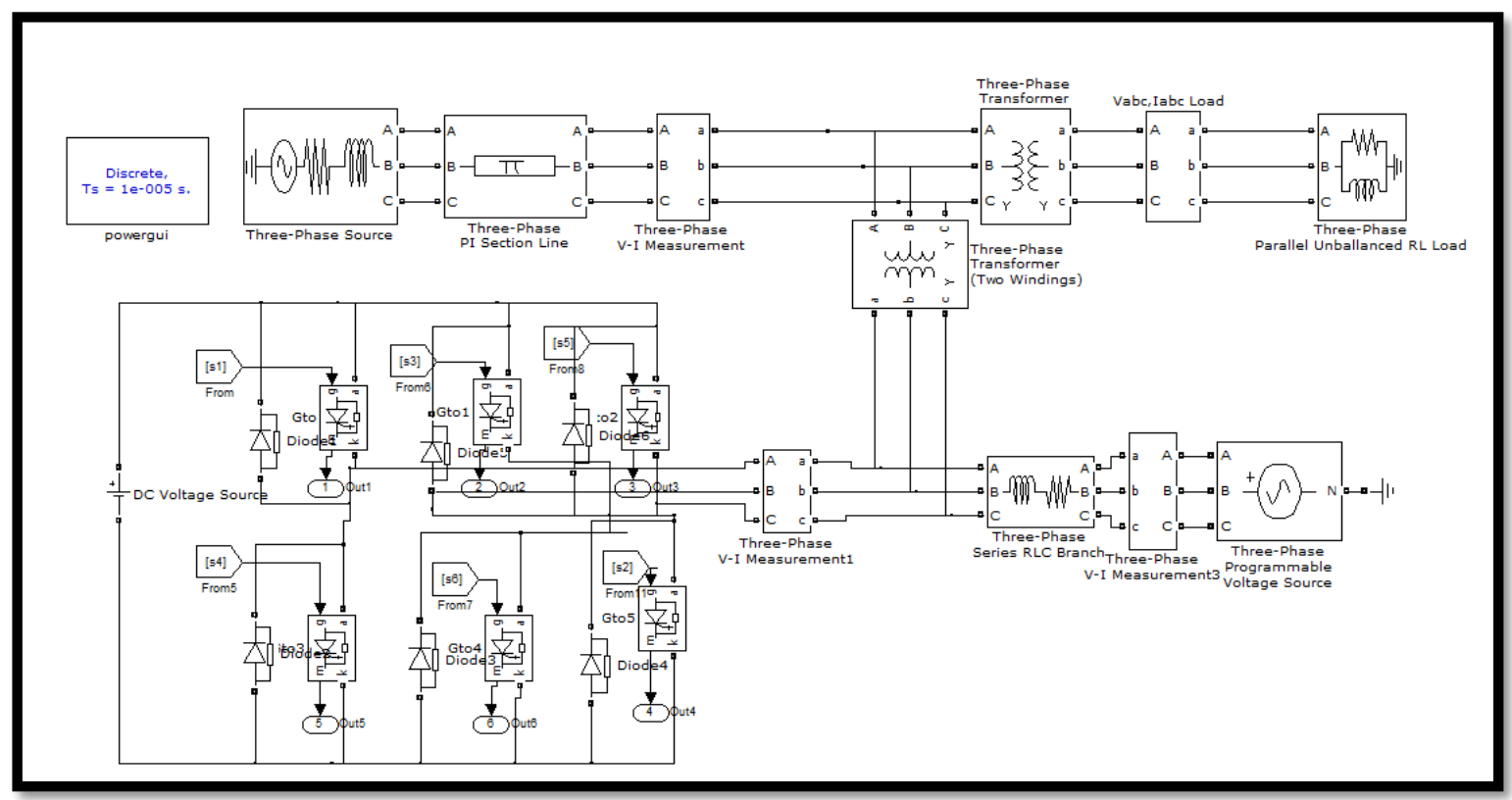

Fig 5.8 Voltage Stability Assessment and Balancing using STATCOM Circuit

Now in the 3-phase unbalancing system we need to mitigate the unbalancing and need to improve stability using FACTs device. So here we provided the STATCOM device for voltage stability assessment and improve the output voltage waveform with the system stability. The STATCOM with 6-pulse converter is shown in the fig 5.6 above and the 
control circuit for that proposed system is shown in the fig 5.7 below. The control scheme includes PLL, abc to dqo transformation, PI controller with PWM controlling for triggering Power electronics devices.

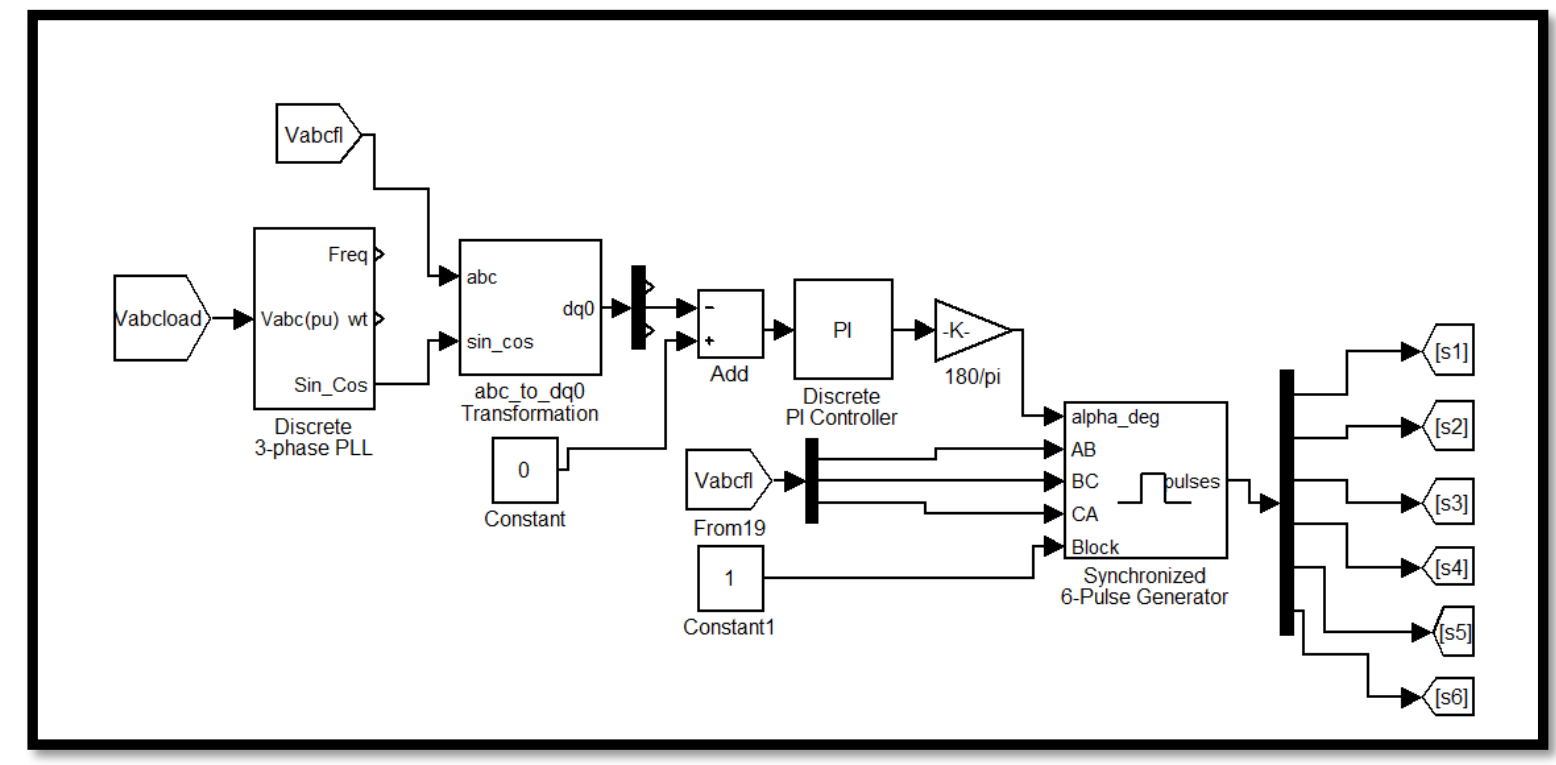

Fig 5.9-Controlling circuit of STATCOM

The control circuit of the proposed System is shown in the fig below. The output voltage is given to the PLL block for phase value and displacement controlling of the 3-phase system. Now the three-phase value is converted from abc to dqo transformation and given to PI controller for error signal providing and finally give to PWM for generate the triggering pulses for the converter of STATCOM device. So, the output of the system is become stable and pure sinusoidal and the load side voltage and current value of the 3 phase system becomes stable. So, we can provide easily the voltage stability assessment the given system with the STATCOM device.

Now the simulation results after providing the control and STATCOM circuit is shown in the fig below. The simulation results show the pure sinusoidal and stable output of voltage and current value in the proposed three phase system. 


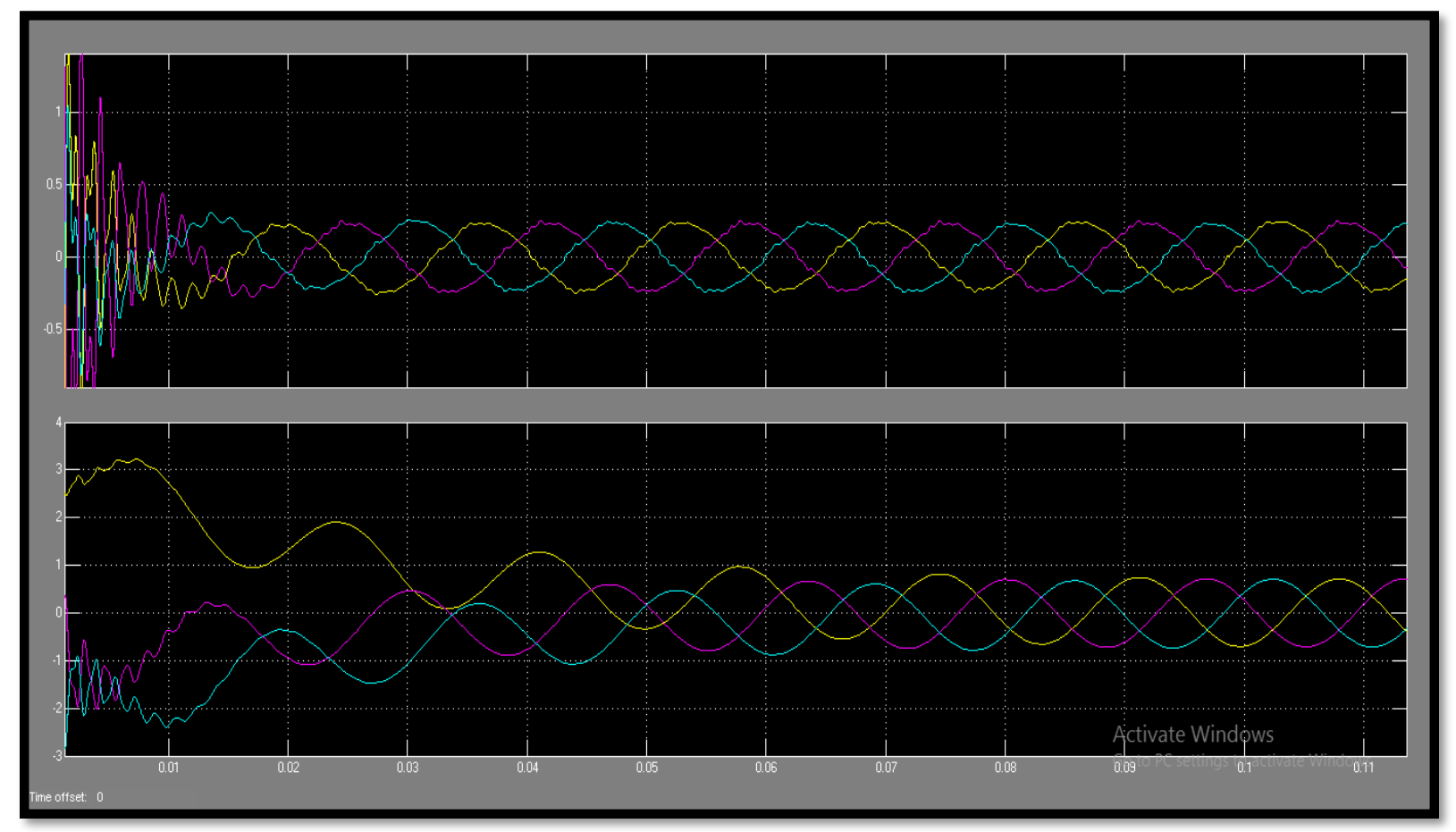

Fig 5.10 Voltage and current enhancement

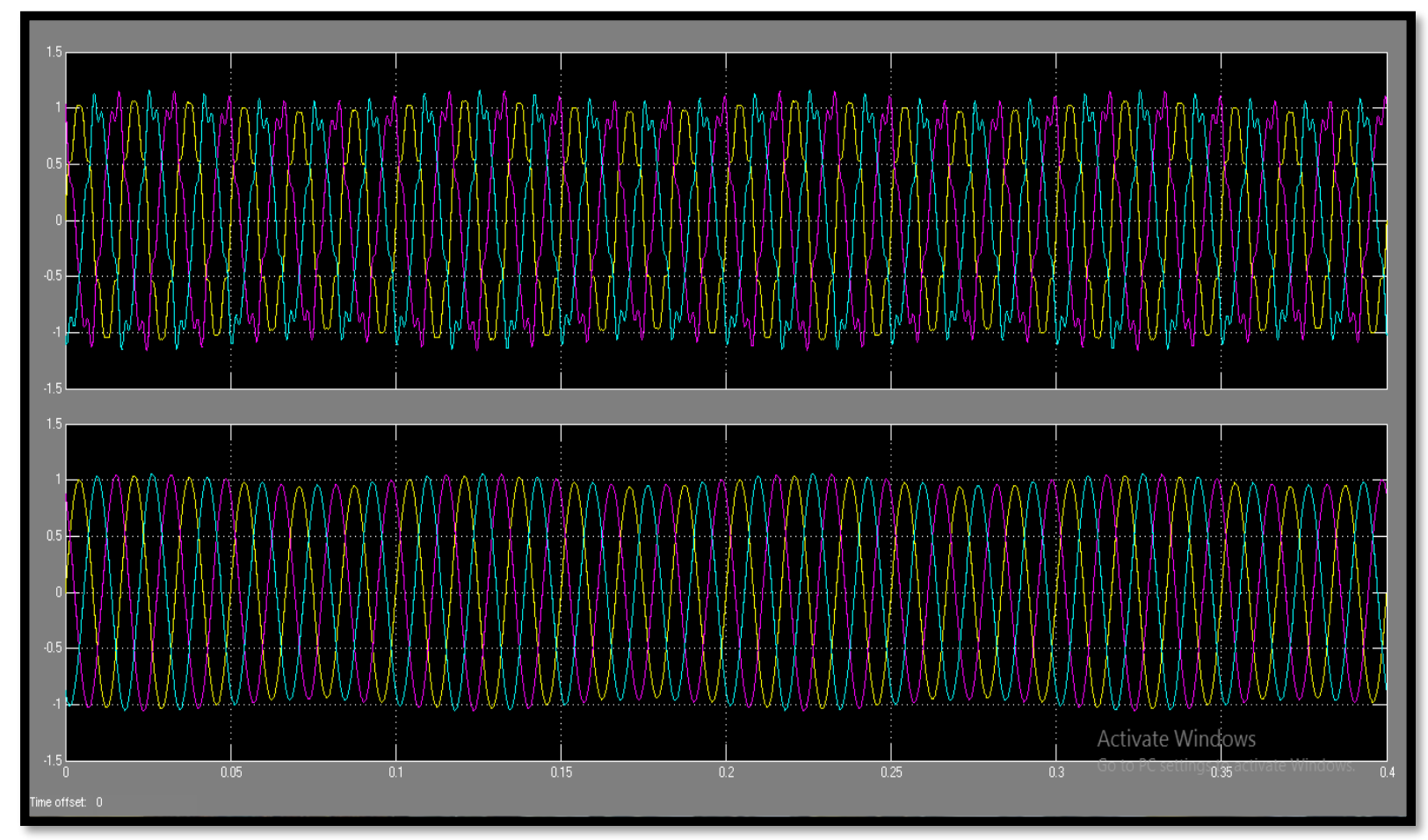

Fig 5.11 load side voltage and current improvement 


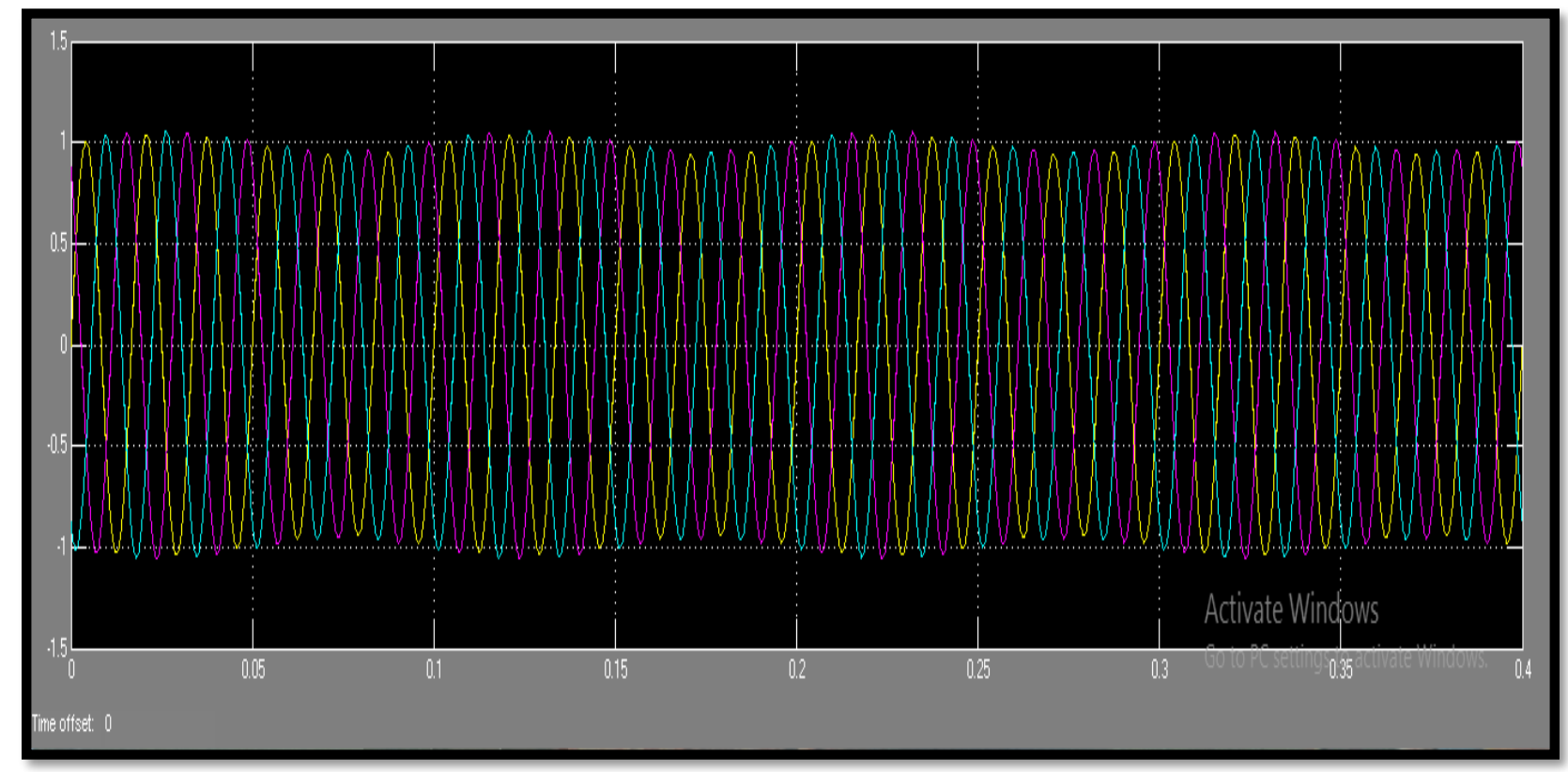

Fig 5.12 Three phase output current in p.u

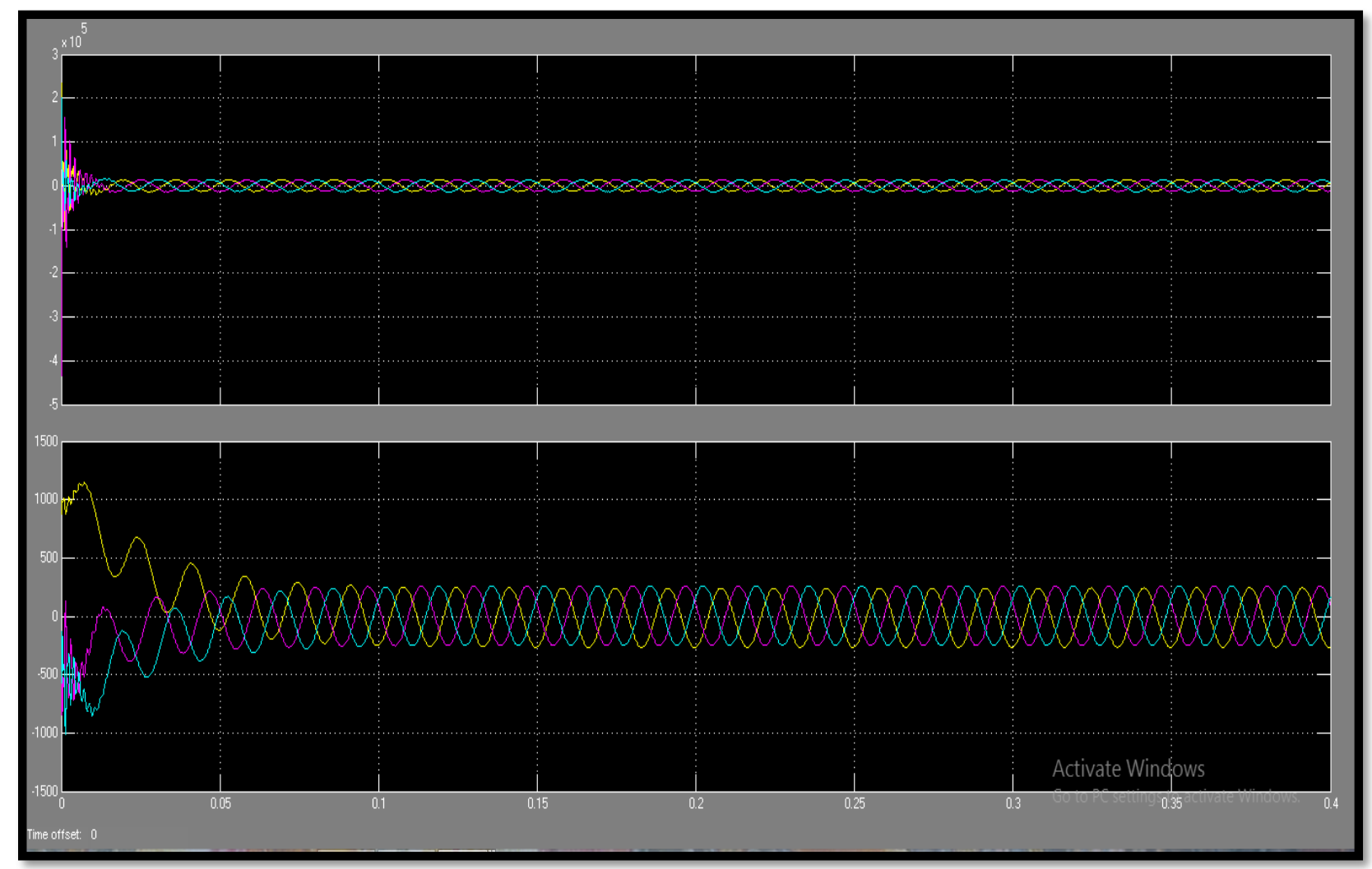

Fig 5.13-Three phase output voltage and current at load side pure sinusoidal after the STATCOM connection 


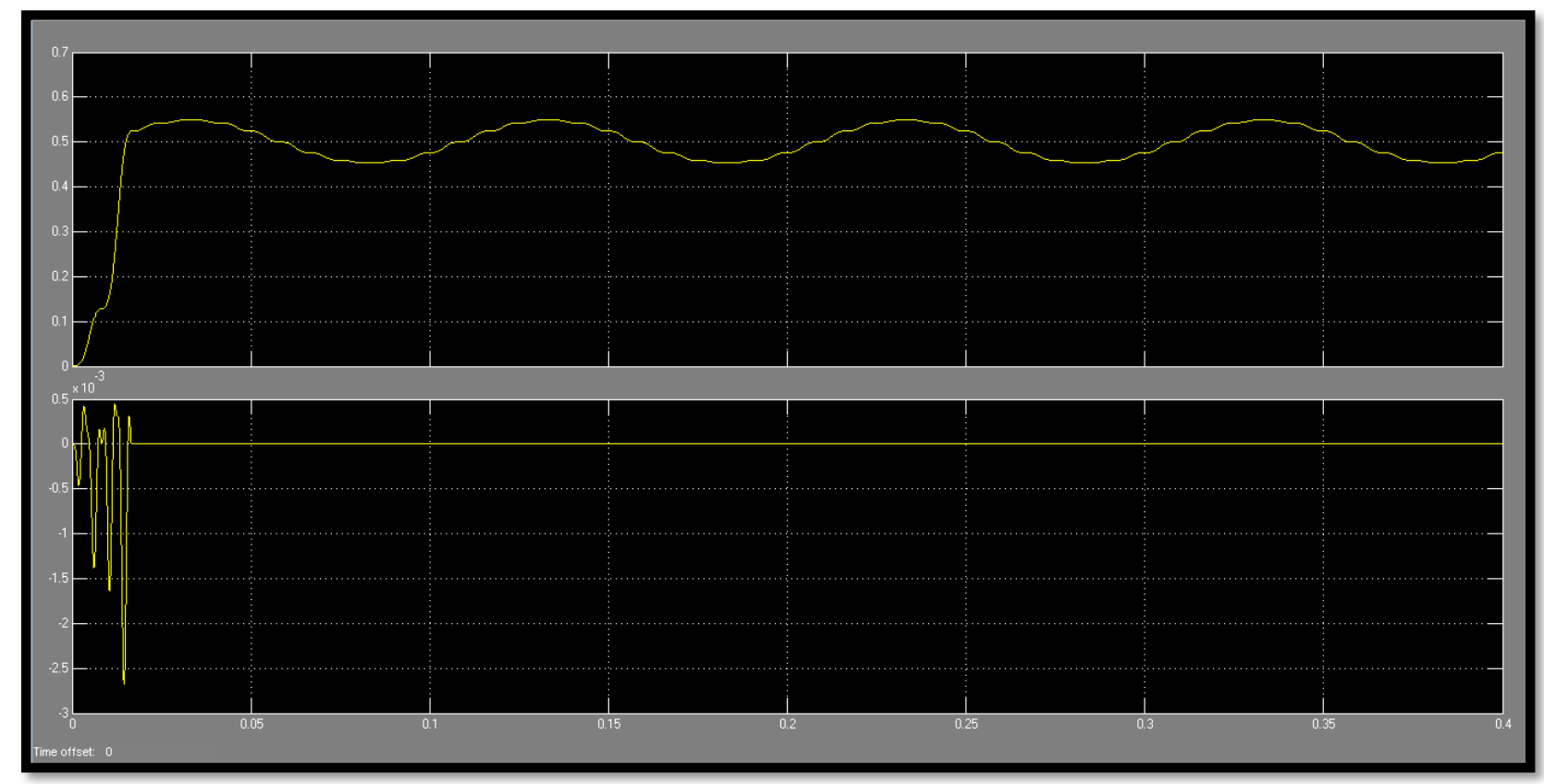

Fig 5.14- Active and Reactive Power after STATCOM

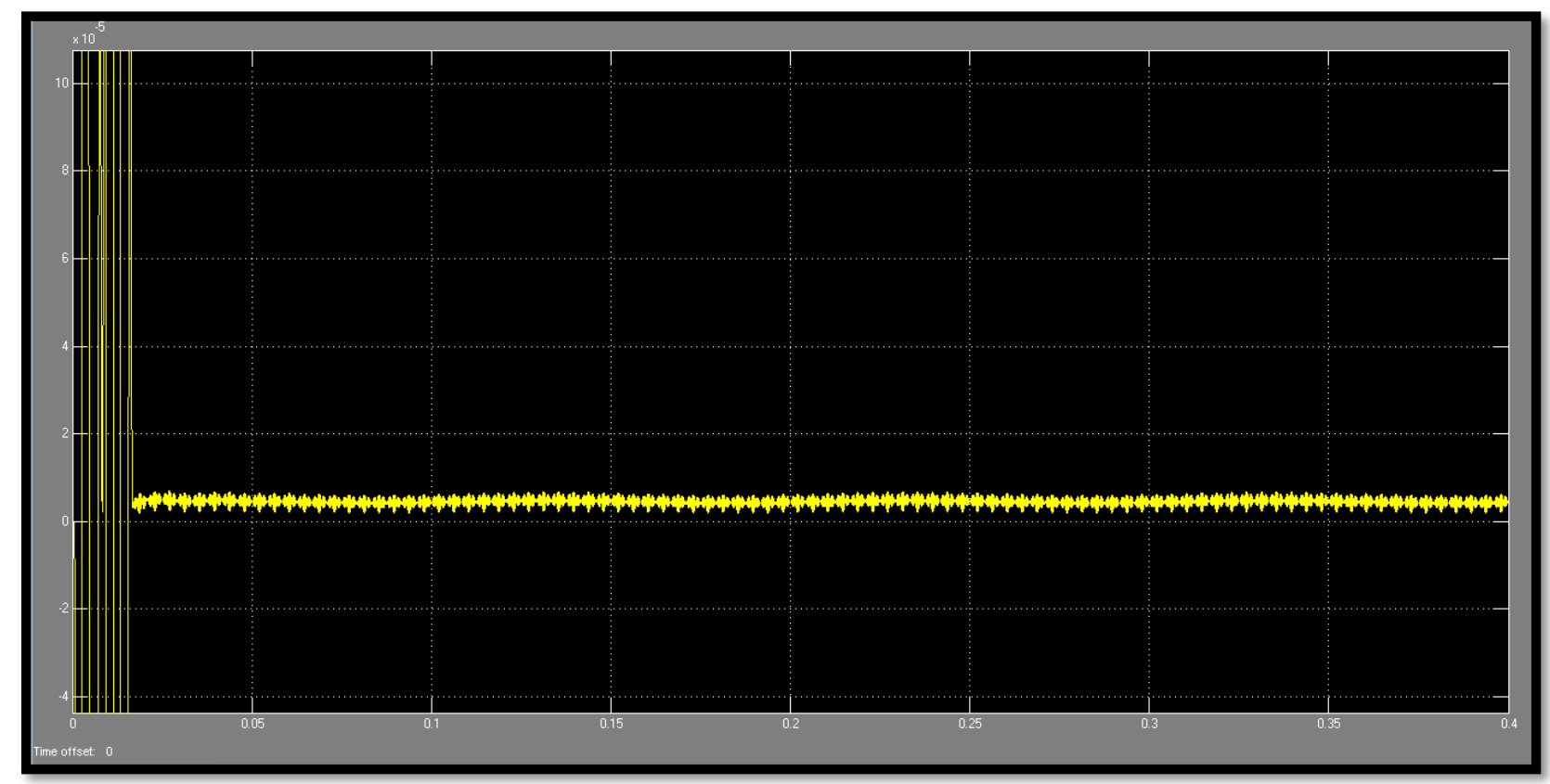

Fig 5.15-Compensated Reactive with STATCOM

THD Analysis After providing the STATCOM in the proposed three phase system the voltage stability improves and output waveforms are also becoming pure sinusoidal \& Stable. Now we can do the THD analysis also from which we can say that the STATCOM integration with the unbalancing circuit is useful and effective. So THD 
analysis shows the improvement in the output voltage stability also. The THD analyses without STATCOM and with STATCOM are shown in the following next section.
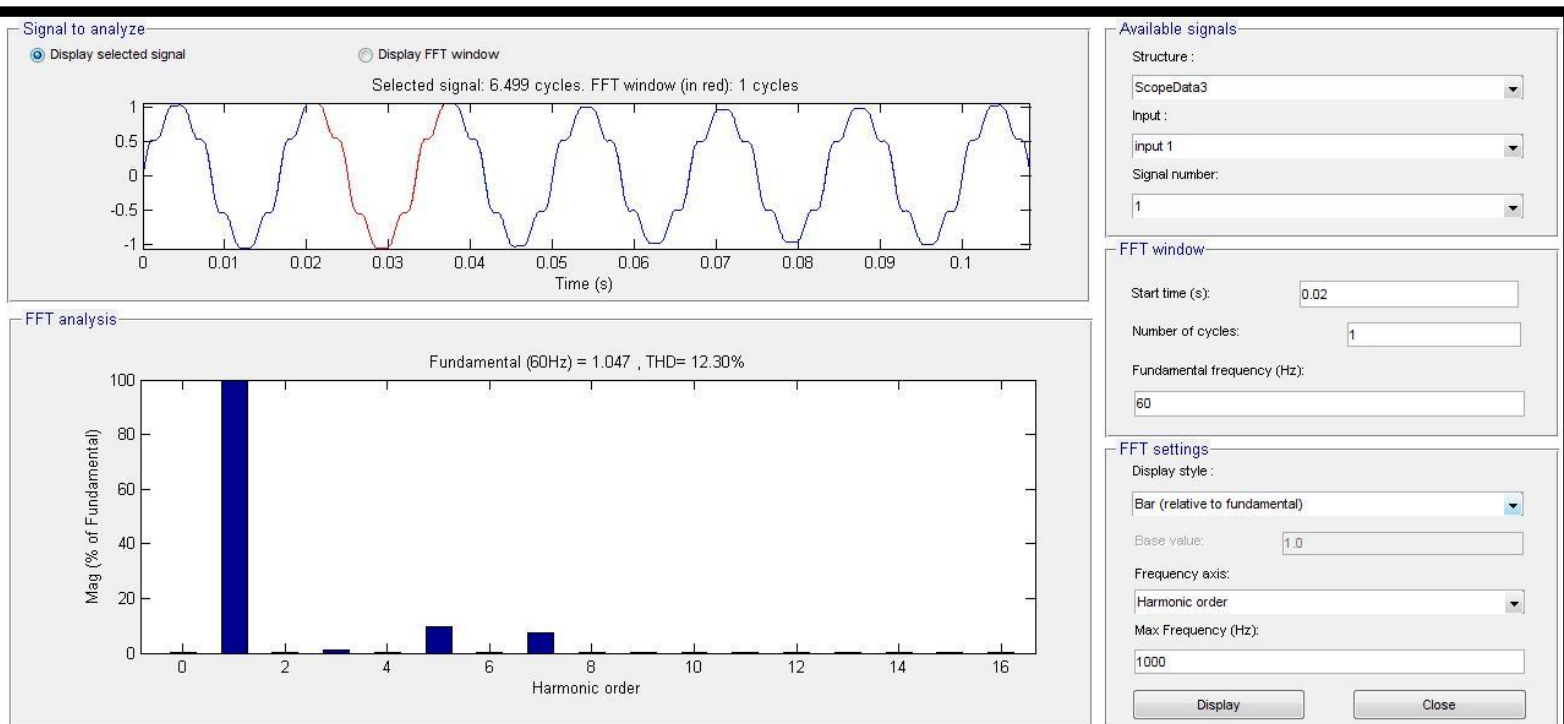

Fig 5.16 -THD before STATCOM connection

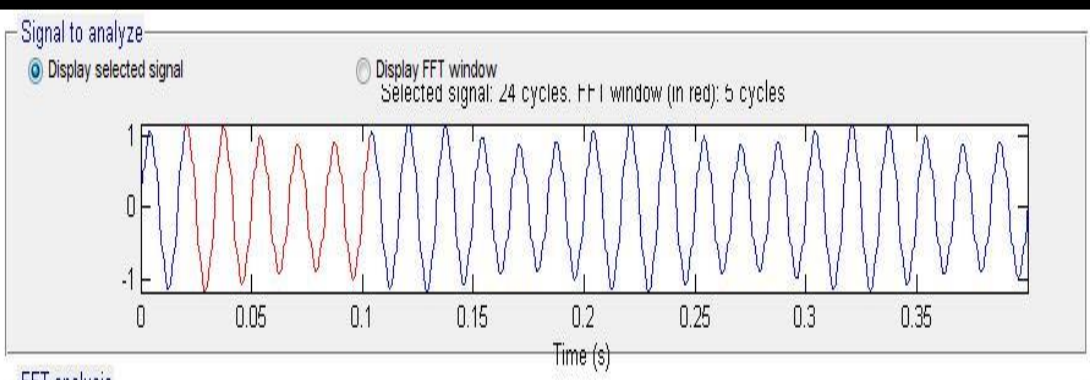

FFT analysis - Fundamental $(60 \mathrm{H} z \mathrm{z})=0.9266, \mathrm{THO}=9.25 \%$
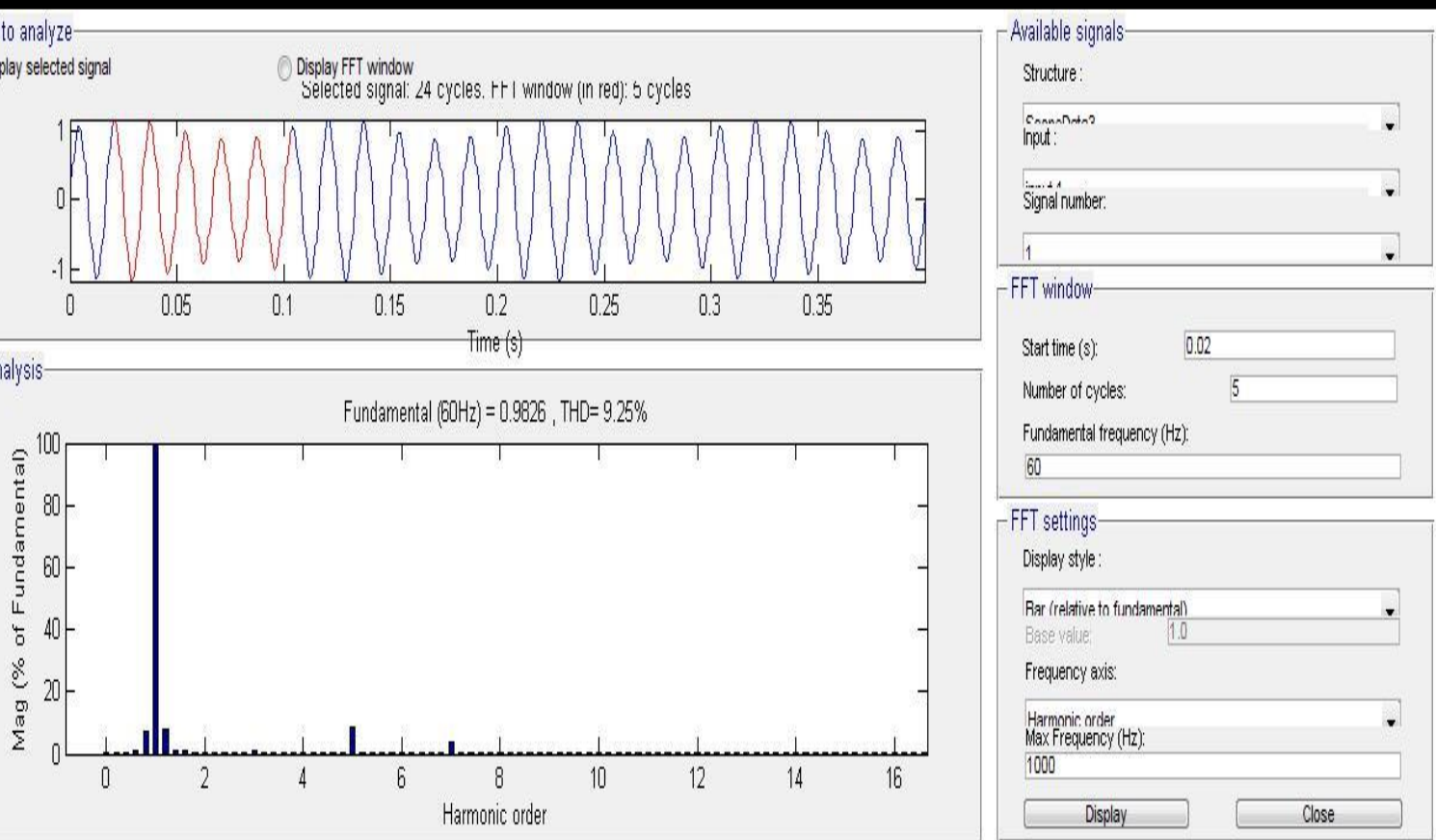

Fig 5.17 -THD after STATCOM connection

The simulation results shows that when the power supply is given to the nonlinear load without any controlling than there is unbalancing and distortion are occurred in the three 
phase system at load side voltage, current and power also. So it is necessary to mitigate that fluctuations and distortion and unbalancing using control strategy of STATCOM. The simulation results of Active and Reactive power shows that the unbalancing is compensated using STATCOM device in the proposed system.

After integrate the STATCOM in the proposed system the power quality is enhanced and we can improve the voltage stability in the 3-phase system. We can also improve the output waveform and mitigate the unbalancing from the proposed three phase system.

\section{CONCLUSION}

This work enhances the understanding of power systems network and power-flow calculations. To analyze the power networks, a power-flow program is developed. It is concluded from the MATLAB modeling and simulation results that the STATCOM improves the voltage magnitude considerably and also improves the voltage stability margin. Also, the model of the STATCOM used under nonlinear load conditions and the voltage unbalancing and distortion has been mitigated by the STATCOM in the proposed system and the overall system performance is also enhanced.

The simulation results show that when the power supply is given to the non-linear load without any controlling than there is unbalancing and distortion are occurred in the threephase system at load side voltage, current and power also. So, it is necessary to mitigate that fluctuations and distortion and unbalancing using control strategy of STATCOM. The simulation results of Active and Reactive power shows that the unbalancing is compensated using STATCOM device in the proposed system. The THD analysis also shows that the voltage stability has been improved with the help of STATCOM in the given system. 


\section{REFERENCES}

[1] Puneet Chawla, Balwinder Singh, "Voltage Stability Assessment and Enhancement Using STATCOM - A Case Study", World Academy of Science, Engineering and Technology International Journal of Electrical, Computer, Energetic, Electronic and Communication Engineering Vol:7, No:12, 2013.

[2] H. B. Nagesh and P. S. Puttaswamy, "Enhancement of Voltage Stability Margin Using FACTS Controllers", International Journal of Computer and Electrical Engineering, Vol. 5, No. 2, April 2013.

[3] Shwetal Patel and Bhavin Trivedi, "VOLTAGE STABILITY ENHANCEMENT USING STATCOM BY CONVENTIONAL ALGORITHM”, ISSN 2319-5991, IJERST Vol. 3, No. 3, August 2014,

[4] Kaushik. B. Patel, Sanjay. R. Vyas, "Review on voltage stability improvement using STATCOM and UPFC", IJSR - INTERNATIONAL JOURNAL OF SCIENTIFIC RESEARCH, Volume-4, Issue-1, January-2015.

[5] Sarita S. Bhole, Prateek Nigam, "Improvement of Voltage Stability in Power System by Using SVC and STATCOM", International Journal of Advanced Research in Electrical, Electronics and Instrumentation Engineering, Vol. 4, Issue 2, February 2015.

[6] Balwant k. Mehta, Asso. Prof. P. J. Patel, "static voltage stability improvement in power system using Statcom facts controller", journal of information, knowledge and research in electrical engineering, issn: 0975 - 6736| nov 12 to oct 13 | volume -02 , issue -02 .

[7] Abhishek Gandhar, Balwinder Singh, Rintu Khanna, " Impacts of Facts TechnologyA State of Art Review", International Journal of Innovative Technology and Exploring Engineering (IJITEE) ISSN: 2278-3075, Volume-1, Issue-4, September 2012.

[8] Tanaya Datta, Palukuru Nagendra, Sunita Halder nee Dey, Subrata Paul, "Voltage stability assessment of a power system incorporating FACTS in equivalent mode" $\mathrm{J}$. Electrical Systems 9-4 (2013): 440-452

[9] Le Ngoc Giang and Liu Kaipei, "Analysis and assessment of STATCOM's effectiveness in improving transient stability for power system", International Journal of Future Generation Communication and Networking Vol.7, No.2 (2014), pp.81-88.

[10] Neena Ramesh, B.V Sanker Ram, Vedam Subrahmanyam, "Voltage Stability Analysis comparing Generator Sensitivity based Method with V-Q Curve Method for Optimal Placement of STATCOM", International Journal of Computer Applications (0975 - 8887) Volume 38- No.12, January 2012. 
[11] C. Barbier and J. P. Barret, "Analysis of Phenomena of Voltage Collapse on a Transmission system," Review Generale de 1Õelectricite, vol. 89, pp. 672690, Oct. 1980.

[12] Miller T. J. E., editor, "Reactive Power Control in Electric Systems," John Wiley \&Sons, New York, 1982.

[13] Saadat H., "Power System Analysis," McGraw-Hill International Editions, vol 17, pp. 114-136, 2004.

[14] Machowski, Bialek and Bumby "Power System Dynamics and Stability" John Wiley \& Sons Ltd, 1997.

[15] Sirisuth, Piya "Voltage Instability analysis using the Sensitivity of Minimum Singular Value of Load Flow Jacobian" 1993.

[16] Ajjarapu, V. and Lee, B. "Bibliography on Voltage Stability" IEEE Trans. on Power Systems, vol. 13, pp.115-125, 1998.

[17] Van Cutsem T. and Vournas C., "Voltage Stability of Electric Power Systems," Springer, Second Printing, 2008.

[18] Bulent Aydin, "Voltage Security Assessment Using P-V and Q-V Curves," Master Project, T.C. Bahcesehir Universitesi, Istanbul, 2008.

[19] Kundur P., "Power System Stability and Control," McGraw-Hill Inc., New York, USA, 1994.

[20] M.H.Haque, 'Optimal location of shunt FACTS devices in long transmission line', IEEE

Proceedings on Generation Transmission \& Distribution, Vol.147, No.4, pp.218-22, 2000.

[21] Chiang H. D., Wang C. S., and Flueck A. J., "Look- Ahead Voltage and Load Margin Contingency Selection Functions for Large-Scale Power Systems," IEEE Transactions on Power Systems, Vol.12, No. 1, pp. 173- 180, Feb. 1997.

[22] "Enhancing the Performance of Watermarking Based on Cat Swarm Optimization Method", IEEE International Conference on Recent Trends in Information Technology, ICRTIT 2011, IEEE, MIT, Anna University, Chennai. June 3-5, 2011.

[23] Bergen R., Power Systems Analysis. Prentice- Hall,New Jersey. 1986. Canizares C.A.,"

Conditions For Saddle-Node Bifurcations In AC/DC Power Systems,”. Int. J. of Electric Power \& Energy Systems, vol. 17, no. 1 February pp.:61-68, 1995. 
[24] N.G. Hingorani, EPR!, "Flexible AC Transmission System," IEEE Spectrum power systems, April 1993, pp. 40-45.

[25] A. M. Gole, V.K. Sood, "A static Compensator model for use with Electromagnetic Transients simulation Programs," IEEE Transactions on Power Delivery, vol. 5, No.3, July 1990, pp. 1398 - 1407.

[26] Cigre international conference on large high voltage Electric systems," Facts Overview", IEEE Power Engineering Society April, 1995. 